\title{
Assessing the Impacts of Two Averaging Methods on AIRS Level 3 Monthly Products and Multiyear Monthly Means
}

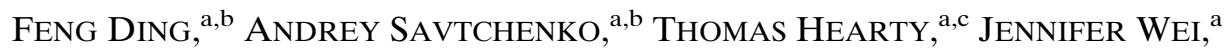 \\ Michael Theobald, ${ }^{\mathrm{a}, \mathrm{b}}$ Bruce Vollmer, ${ }^{\mathrm{a}}$ BAiJun Tian, ${ }^{\mathrm{d}}{ }^{\mathrm{a}}$ AND ERIC Fetzer ${ }^{\mathrm{d}}$ \\ ${ }^{a}$ Goddard Earth Sciences Data and Information Services Center, NASA Goddard Space Flight Center, Greenbelt, Maryland \\ ${ }^{\mathrm{b}}$ ADNET Systems, Greenbelt, Maryland \\ ${ }^{\mathrm{c}}$ Stinger Ghaffarian Technologies, Greenbelt, Maryland \\ ${ }^{\mathrm{d}}$ Jet Propulsion Laboratory, California Institute of Technology, Pasadena, California
}

(Manuscript received 2 August 2019, in final form 30 March 2020)

\begin{abstract}
The Atmospheric Infrared Sounder (AIRS) on board NASA's Aqua satellite provides more than 16 years of data. Its monthly gridded (Level 3) product has been widely used for climate research and applications. Since counts of successful soundings in a grid cell are used to derive monthly averages, this averaged by observations $(\mathrm{ABO})$ approach effectively gives equal importance to all participating soundings within a month. It is conceivable then that days with more observations due to day-to-day orbit shift and regimes with better retrieval skills will contribute disproportionately to the monthly average within a cell. Alternatively, the AIRS Level 3 monthly product can be produced through an averaged by days (ABD) approach, where the monthly mean in a grid cell is a simple average of the daily means. The effects of these averaging methods on the AIRS version 6 monthly product are assessed quantitatively using temperature and water vapor at the surface and $500 \mathrm{hPa}$. The $\mathrm{ABO}$ method results in a warmer (slightly colder) global mean temperature at the surface $(500 \mathrm{hPa})$ and a drier global mean water vapor than ABD method. The AIRS multiyear monthly mean temperature and water vapor from both methods are also compared with the Modern-Era Retrospective Analysis for Research and Applications version 2 (MERRA-2) product and evaluated with a simulation experiment, indicating the ABD method has lower error and is more closely correlated with MERRA-2. In summary, the ABD method is recommended for future versions of the AIRS Level 3 monthly product and more data services supporting Level 3 aggregation are needed.
\end{abstract}

\section{Introduction}

The Atmospheric Infrared Sounder (AIRS) is a hyperspectral infrared sounder on board NASA's Aqua satellite, which was launched in May 2002 into a sun-synchronous polar orbit (Aumann et al. 2003). "AIRS" also refers to an instrument suite comprised of AIRS and two multichannel microwave instruments, the Advanced Microwave Sounding Unit (AMSU) and the Humidity Sounder for Brazil (HSB). As HSB ceased operations at a very early stage of the AIRS mission, AIRS observations consist of measurements made only by AIRS and AMSU for most of the mission duration. The Aqua satellite orbits at an altitude of $705 \mathrm{~km}$, with a track that takes it northward (daytime/ascending) across the equator at approximately 1330 local time, and southward (nighttime/descending) across the equator at

Corresponding author: Feng Ding, feng.ding@nasa.gov approximately 0130 local time (Parkinson 2003). As the satellite orbits, AIRS scans from side to side, observing Earth's surface in an orbital swath pattern. Aqua has a 16-day orbital repeat cycle, and its sun-synchronous polar orbit enables more observations in higher latitudes due to overlapping orbits and twice per day in lower latitudes.

AIRS provides observations of the atmospheric state relevant to the global water and energy balance, which include temperature and water vapor profiles, outgoing longwave radiation, cloud properties, and trace gases. The NASA Goddard Earth Sciences Data and Information Services Center (GES DISC) has been curating the processing, archiving, and distribution of AIRS data since launch. The GES DISC, in collaboration with the NASA Sounder Team at the Jet Propulsion Laboratory (JPL), released the AIRS product from the version 6 algorithm in early 2013. The version 6 algorithm represents a significant improvement over previous versions with greater stability, yield, and quality of data products (Susskind et al. 2014). 
There are three levels of AIRS products: Level 1 radiances, Level 2 retrieval parameters, and Level 3 globally gridded averages. To study phenomena on large temporal and spatial scales, users often prefer the AIRS Level 3 products, which contain geophysical parameters gridded to a $1^{\circ} \times 1^{\circ}$ latitude-longitude grid, with gridcell coordinates ranging from $-180^{\circ}$ to $+180^{\circ}$ in longitude, and $-90^{\circ}$ to $+90^{\circ}$ in latitude. Averaging methods can have considerable impact on deriving multiday Level 3 products from Level 2 products. Levy et al. (2009) studied the impact of different averaging methods to derive Level 3 monthly products using Moderate Resolution Imaging Spectroradiometer (MODIS) retrieved aerosol optical depth data. They found the impacts vary by region and result in global mean estimates varying by $30 \%$ or more. Smith et al. (2013) proposed a uniform space-time gridding algorithm for satellite data and studied its sensitivity to grid size, number of days, and viewing angle restrictions. Guan et al. (2013) thoroughly studied the satellite orbital sampling impacts on the comparison between satellite observation and climate model, which included Aqua and AIRS.

The current AIRS Level 3 products are derived from the Level 2 swath (satellite raster) observations by first gridding and averaging successfully retrieved Level 2 field-of-regards (FOR) soundings (i.e., quality screened) onto $1^{\circ} \times 1^{\circ}$ latitude-longitude daily grid cells. The ascending/daytime and descending/nighttime orbits are gridded and averaged separately. During this process, the count of contributing Level 2 observations in a daily grid cell is preserved and used to derive the 8-day (half of the Aqua repeat cycle) and monthly gridded products (Tian et al. 2013b). In effect, this approach gives equal weight to all contributing Level 2 observations in a grid cell, for all Level 3 gridded products. More importantly, it also means that those days with more Level 2 observations due to day-to-day orbit shift (more notable in the tropics and subtropics) and those days when the retrieval algorithm has better skill and higher yields, will statistically dominate when calculating the monthly average. This dominance is not an algorithm computational step, but emerges from the averaging process. We will refer to this averaging approach as averaged by observations (ABO) throughout this paper's discussion.

The current AIRS Level 3 monthly average is statistically sound because it gives more weight to conditions that are more frequently observed. However, physically, it retains a potential pitfall of bias toward days with more orbit passes and weather regimes where the retrieval algorithm has better skill. The simplest approach to alleviate this skewed sampling is to derive the monthly averages from the daily means, without regard to counts of observations. In contrast to $\mathrm{ABO}$, we will call this approach "unweighted" averaging in terms of each day and refer to it as averaged by days (ABD) in this paper.

This study aims to evaluate the difference between monthly products derived by the $\mathrm{ABO}$ and $\mathrm{ABD}$ methods, and hence the weighting impact on the multiyear monthly mean that is used in climate studies. The next section describes in detail the two averaging methods. Section 3 lists the datasets and tools used for the study. Section 4 presents the evaluation results and analysis. Section 5 shows the comparison of two averaging methods with other climatology products and evaluation with a simulation experiment. Last, we summarize the results and give recommendations for future AIRS Level 3 products and data services in NASA GES DISC.

\section{ABO versus ABD averaging for AIRS monthly product}

AIRS data are intended to improve numerical weather prediction (NWP) and provide high-quality research data for climate studies (Chahine et al. 2006). AIRS hyperspectral infrared data have shown significant positive impact on the forecast skill of operational NWP (Marshall et al. 2006). Regarding climate investigations, the current 16-yr record of AIRS monthly data has been widely used in several arenas. Examples of such usage include short-term climate research and as an observational component for model evaluation. For instance, AIRS monthly temperature and humidity profile products have been published as one of many Observations for Model Intercomparison Projects (Obs4MIPs) datasets (Tian et al. 2013a, 2019) and they have been widely used in the climate model evaluation for the phase 5 of the Coupled Model Intercomparison Project (CMIP5) (Tian et al. 2013a; Tian 2015). Susskind et al. (2019) found that recently observed global warming was confirmed by AIRS data.

Currently the AIRS standard monthly product is generated by the ABO approach. It is a "weighted" average of daily means, where the counts of successful retrievals in a $1^{\circ} \times 1^{\circ}$ grid cell for each day serve as weights. The days with more valid counts have more weights in the monthly average. The day-to-day variations of valid counts arise from the orbit shift and retrieval algorithm. Even if the count variation by the orbit shift can be assumed as random, the AIRS retrieval yields more in certain weather regimes. Hence, randomness of sampling, and the applicability of a weighted average, do not strictly apply. For example, since the AIRS retrieval succeeds in conditions with cloud cover less than 90\% (Susskind et al. 2003), the standard 


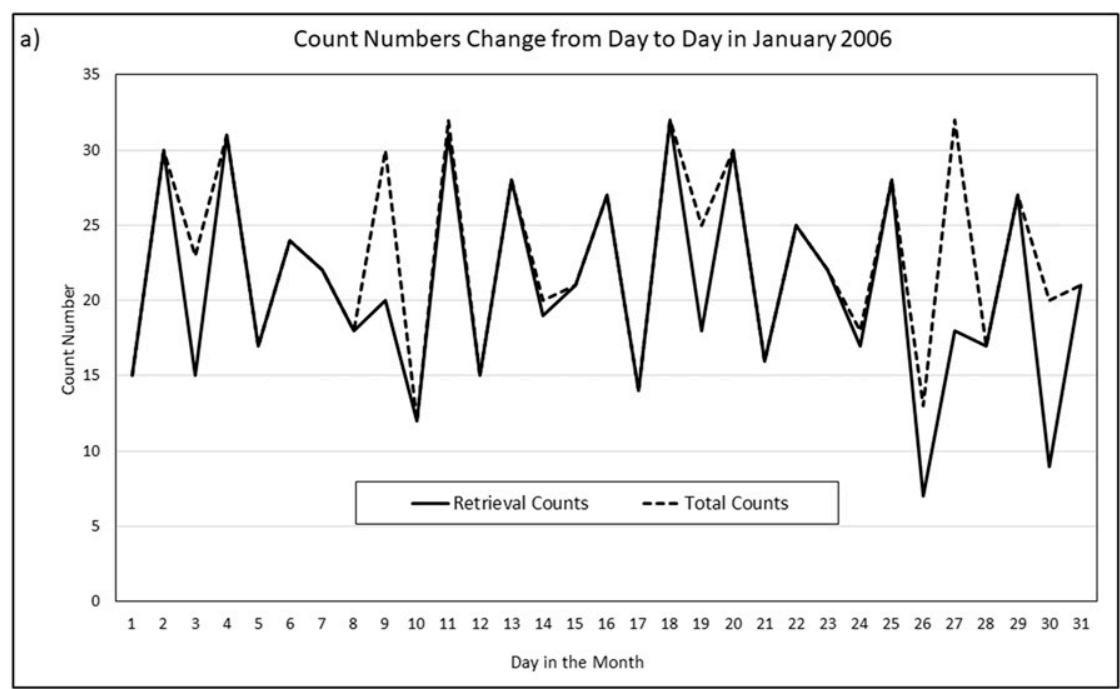

b) Total Counts for Daytime/Ascending Surface Air Temperature, January 2006

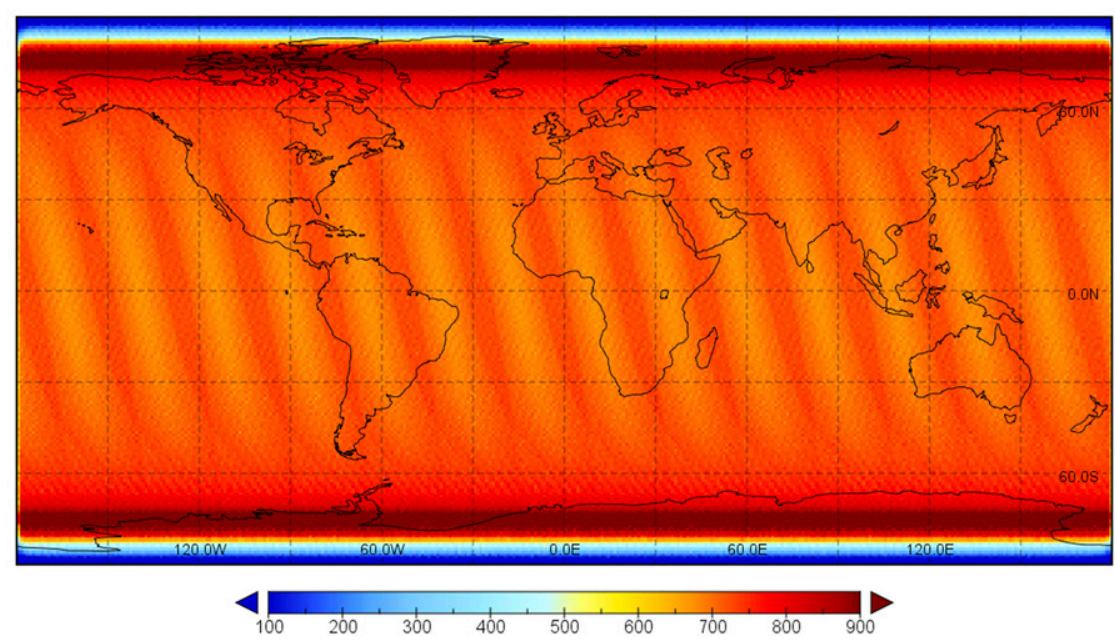

FIG. 1. (a) Total counts and valid retrieval counts of AIRS Level 2 daytime/ascending surface air temperature averaged in the Level 3 daily product at a grid cell $\left(50.5^{\circ} \mathrm{N}, 99.5^{\circ} \mathrm{W}\right)$ for each day of January 2006 and (b) the total counts map in January 2006.

monthly product is an estimate that may be slightly biased toward clearer conditions. Considering that counts will consistently weigh in favor of less-cloudy conditions, sampling biases may become more significant and consistent in multiyear climatological estimates.

Figure 1 gives an example of how the ABO approach favors days with more valid retrievals in a grid cell of a Level 3 monthly product. Figure 1a shows the day-to-day variations of the counts of total samples (dashed line) and the counts with valid Level 2 retrieved daytime/ascending surface air temperature (solid line) in one grid cell centered at $50.5^{\circ} \mathrm{N}, 99.5^{\circ} \mathrm{W}$ of the Level 3 daily product in January 2006. The total counts in a day is the maximum number that any retrieval algorithm may reach in this grid cell for that day, and is fully determined by the orbital path. It can be seen that the total counts (dashed line) already showed remarkable change from day to day, which is purely due to the orbit shift. The dashed line follows the 16-day repeat cycle of Aqua orbit: day 1 matches day 17, day 2 matches day 18, etc. After the retrieval, the valid counts (solid line) changed significantly, with the smallest count equal to 7 on 26 January, and the largest count equal to 32 on 18 January. This indicates that when averaging data in this grid box over January 2006 using the ABO method, the temperature on 18 January gets a weight more than 4 times greater than that for the temperature on 26 January.

Figure $1 \mathrm{~b}$ is the map of daytime/ascending total counts in January 2006, and shows the spatial variations of total counts from day-to-day orbit shift. In the low-latitude 
TABLE 1. Global statistical results for 14 years.

\begin{tabular}{|c|c|c|c|c|}
\hline Variable name & MAD (K) & RMSD (K) & Minimum (K) & Maximum (K) \\
\hline $\begin{array}{l}\text { Surface air temperature } \\
\text { (daytime/ascending) }\end{array}$ & 0.0781 & 0.3090 & -4.76 & 5.37 \\
\hline $\begin{array}{l}\text { Surface air temperature } \\
\text { (nighttime/descending) }\end{array}$ & 0.0623 & 0.3031 & -5.38 & 8.34 \\
\hline $\begin{array}{l}\text { Surface skin temperature } \\
\text { (daytime/ascending) }\end{array}$ & 0.1704 & 0.5899 & -13.32 & 11.85 \\
\hline $\begin{array}{l}\text { Surface skin temperature } \\
\text { (nighttime/descending) }\end{array}$ & 0.1130 & 0.4777 & -8.94 & 11.55 \\
\hline
\end{tabular}

areas, the red and yellow alternating stripes follow the pattern of orbital paths. In high-latitude areas, the counts are large and about the same along the longitudes. The counts are smaller near the poles.

To study the impacts due to this weighting approach, a prepared unweighted monthly product was compared with the weighted product, that is, the standard AIRS monthly product. This unweighted monthly product is derived from the AIRS daily standard product using the ABD method, where each count of valid retrievals in a grid cell is disregarded and thus each day with valid data has equal weight. In the January 2006 case, when

a)

Daytime/Ascending Surface Air Temperature Difference, January 2006

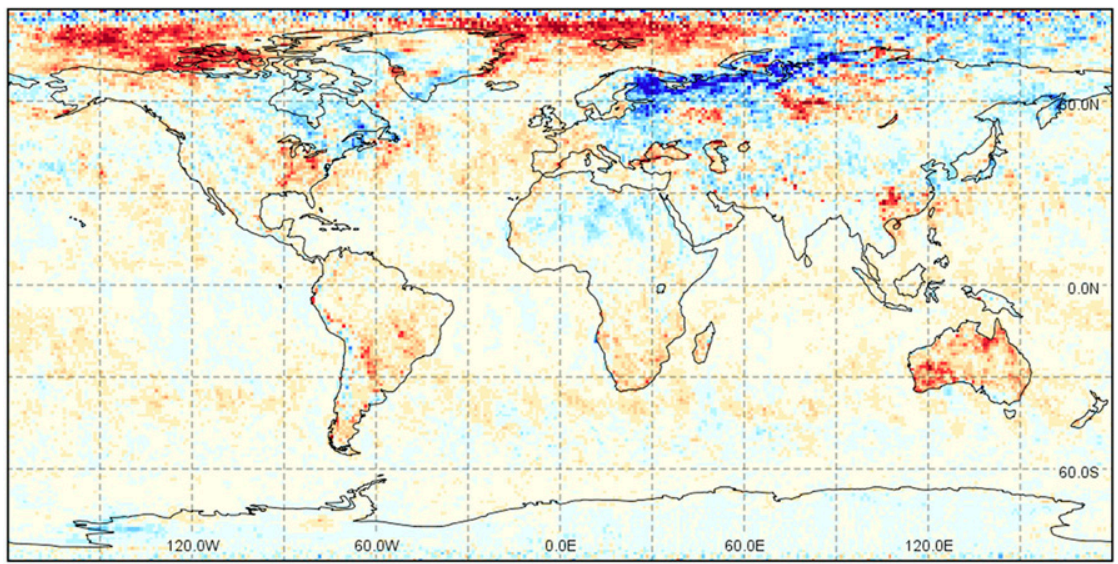

b) Daytime/Ascending Surface Skin Temperature Difference, January 2006

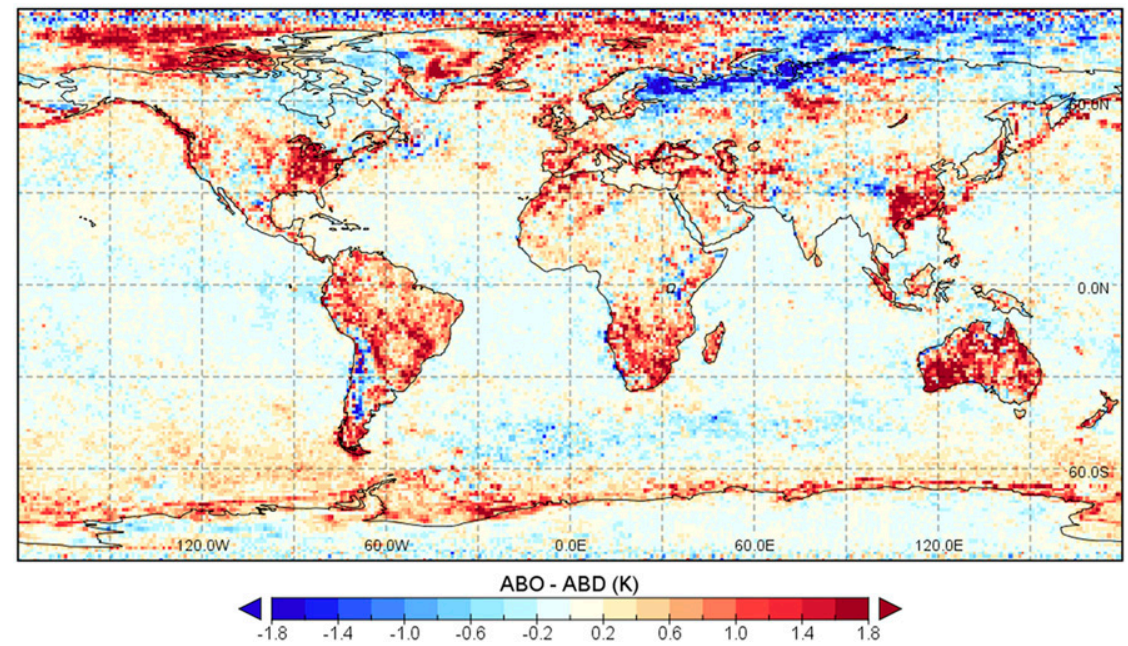

FIG. 2. Maps of difference (ABO - ABD) of daytime/ascending (a) surface air and (b) surface skin temperature in January 2006 using AIRS data. 
a)

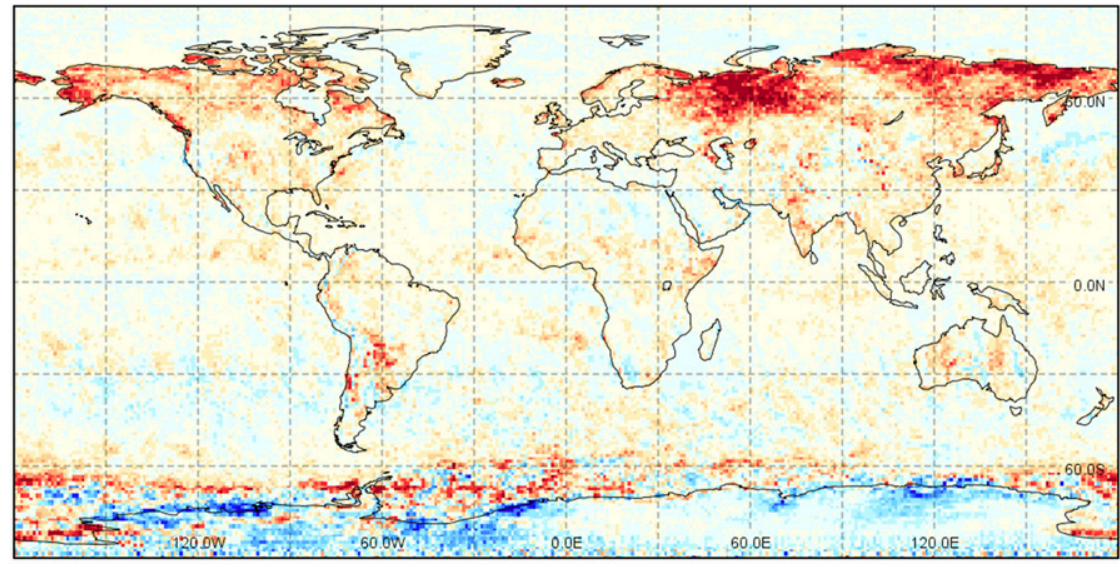

b)

Daytime/Ascending Surface Skin Temperature Difference, July 2006

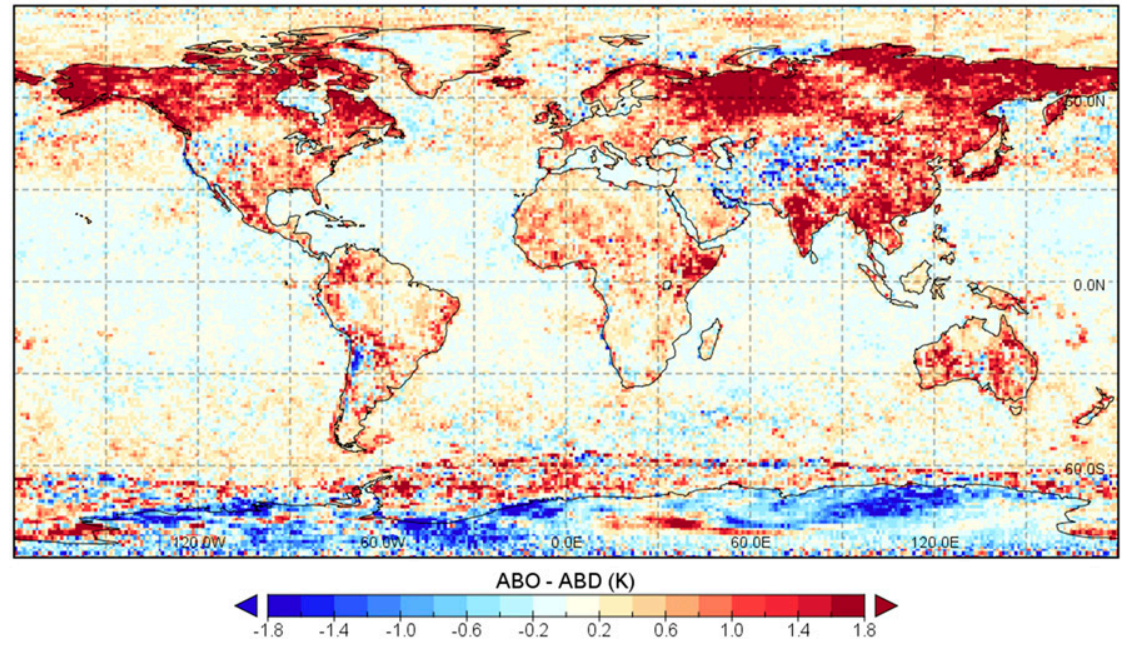

FIG. 3. As in Fig. 2, but for July 2006.

producing the unweighted monthly surface air temperature in the grid cell $\left(50.5^{\circ} \mathrm{N}, 99.5^{\circ} \mathrm{W}\right)$ using the ABD method, the temperature in the grid cell $\left(50.5^{\circ} \mathrm{N}\right.$, $99.5^{\circ} \mathrm{W}$ ) on $26 \mathrm{January}$ gets the same weight as the one on 18 January, even though 18 January has many more valid observations in the grid cell than 26 January.

\section{Datasets and tools}

The datasets used for this work are the AIRS version 6 standard retrieval monthly product with the short name AIRX3STM (AIRS Science Team/Joao Teixeira 2013a; Tian et al. 2013b), and the daily product with the short name AIRX3STD (AIRS Science Team/Joao Teixeira 2013b; Tian et al. 2013b) over 14 years, September 2002 to August 2016. This data period is used because the AMSU-A2 instrument ceased working on 24 September 2016. Temperature and water vapor, two of the most essential parameters in AIRS retrievals, at the surface and one upper level $(500 \mathrm{hPa})$ for both nodes, ascending/daytime and descending/nighttime, are selected for this study. For the temperature at the surface, both surface air and skin temperatures are studied. For water vapor, the selected parameter is water vapor mass mixing ratio (MMR). The monthly means of temperature and water vapor from the $\mathrm{ABO}$ approach are simply a subset of the AIRX3STM product.

Giovanni (Acker and Leptoukh 2007; Liu and Acker 2017; https://giovanni.gsfc.nasa.gov), a web-based application tool developed by the GES DISC, provides a simple and intuitive way to visualize, analyze, and access vast amounts of Earth science remote sensing data without having to download the data. We have curated the most important variables from AIRS version 6 products into Giovanni. For the purposes of this analysis, the "time-averaged map" function in Giovanni was 
a)
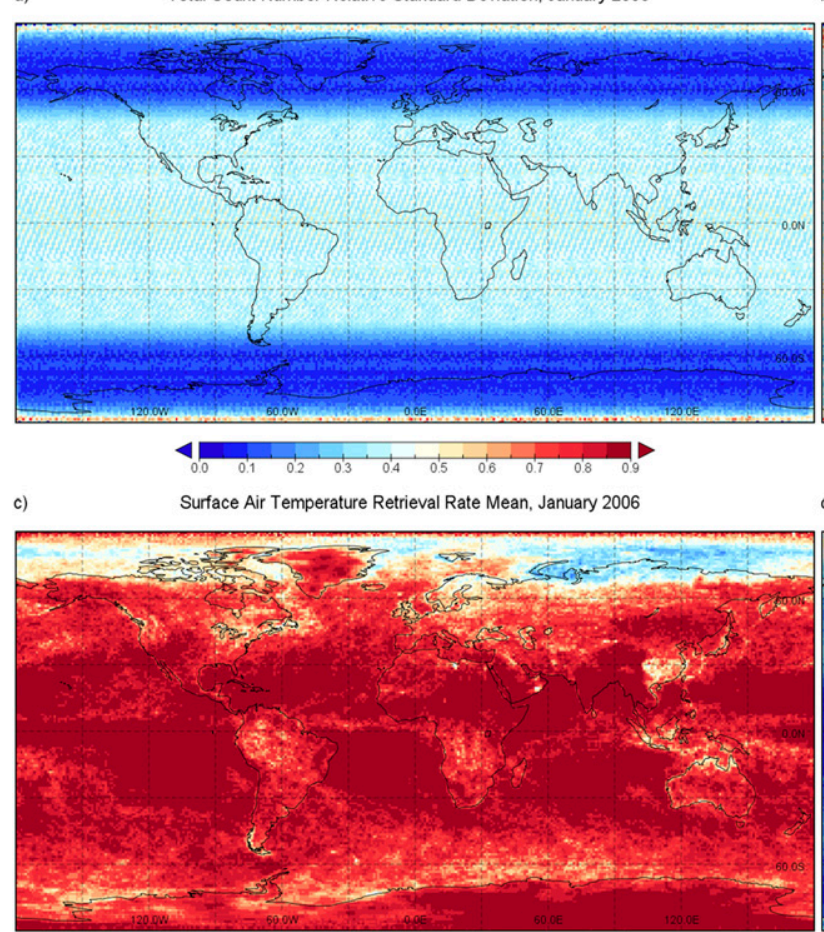

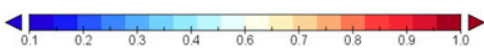

b) Valid Retrieval Count Number Relative Standard Deviation, January 2006

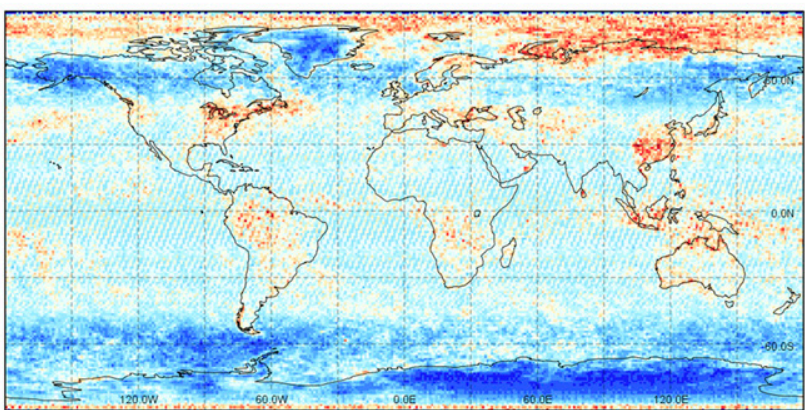

d)

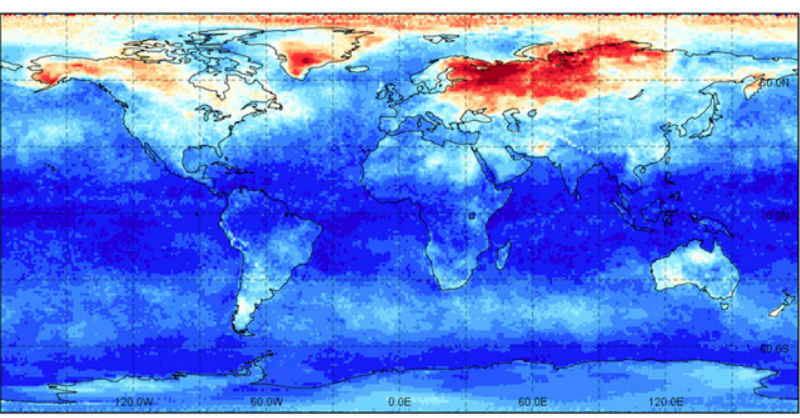

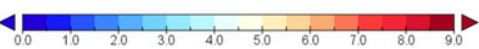

FIG. 4. Maps of relative standard deviation of (a) total counts and (b) valid retrieval counts, as well as (c) retrieval yield-rate mean and (d) temperature standard deviation from daily AIRS daytime/ascending surface air temperature in January 2006.

used to produce the monthly product from the ABD method. This function in Giovanni directly calculates the average of all days with valid observations during the input date range without any weighting, which is essentially the ABD approach. The AIRS daily temperature and water vapor MMR from the AIRX3STD product in Giovanni are processed by the time-averaged map function by inputting the date range of each month from September 2002 to August 2016. The resulting netCDF files from the time-averaged map function in Giovanni are subsequently downloaded as the monthly means from the ABD method. This process is repeated

TABLE 2. Statistical results for daytime/ascending surface air temperature and surface skin temperature in January for 14 years of AIRS data.

\begin{tabular}{|c|c|c|c|c|c|c|c|c|}
\hline \multirow[b]{2}{*}{ Year } & \multicolumn{2}{|c|}{ MAD (K) } & \multicolumn{2}{|c|}{ RMSD (K) } & \multicolumn{2}{|c|}{ Minimum (K) } & \multicolumn{2}{|c|}{ Maximum (K) } \\
\hline & $\begin{array}{l}\text { Surface } \\
\text { air temp }\end{array}$ & $\begin{array}{c}\text { Surface } \\
\text { skin temp }\end{array}$ & $\begin{array}{l}\text { Surface } \\
\text { air temp }\end{array}$ & $\begin{array}{c}\text { Surface } \\
\text { skin temp }\end{array}$ & $\begin{array}{l}\text { Surface } \\
\text { air temp }\end{array}$ & $\begin{array}{c}\text { Surface } \\
\text { skin temp }\end{array}$ & $\begin{array}{l}\text { Surface } \\
\text { air temp }\end{array}$ & $\begin{array}{c}\text { Surface } \\
\text { skin temp }\end{array}$ \\
\hline 2003 & 0.0598 & 0.1242 & 0.2923 & 0.4824 & -2.19 & -3.91 & 2.83 & 8.24 \\
\hline 2004 & 0.1777 & 0.2337 & 0.4879 & 0.6552 & -2.54 & -4.65 & 5.37 & 6.55 \\
\hline 2005 & 0.0740 & 0.1454 & 0.3153 & 0.5199 & -2.74 & -4.73 & 3.35 & 5.36 \\
\hline 2006 & 0.0852 & 0.1412 & 0.3323 & 0.5521 & -3.04 & -4.14 & 2.51 & 6.85 \\
\hline 2007 & 0.0719 & 0.1298 & 0.2966 & 0.4944 & -2.72 & -5.02 & 2.57 & 5.12 \\
\hline 2008 & 0.0954 & 0.1720 & 0.3175 & 0.5525 & -2.11 & -3.98 & 4.45 & 7.47 \\
\hline 2009 & 0.0620 & 0.1206 & 0.3216 & 0.5129 & -2.70 & -4.87 & 3.08 & 5.14 \\
\hline 2010 & 0.0916 & 0.1699 & 0.4083 & 0.6598 & -3.52 & -6.34 & 4.32 & 5.84 \\
\hline 2011 & 0.0761 & 0.1294 & 0.3405 & 0.5477 & -2.80 & -3.98 & 3.31 & 4.90 \\
\hline 2012 & 0.0921 & 0.1506 & 0.3422 & 0.5165 & -2.72 & -3.32 & 3.34 & 5.48 \\
\hline 2013 & 0.0898 & 0.1550 & 0.3388 & 0.5033 & -3.22 & -5.22 & 3.19 & 6.00 \\
\hline 2014 & 0.0661 & 0.1341 & 0.3496 & 0.5345 & -3.23 & -4.82 & 3.11 & 5.02 \\
\hline 2015 & 0.0773 & 0.1474 & 0.3175 & 0.5144 & -2.52 & -3.08 & 2.85 & 5.17 \\
\hline 2016 & 0.0773 & 0.1493 & 0.3830 & 0.5684 & -3.50 & -4.20 & 3.22 & 6.88 \\
\hline
\end{tabular}


TABLE 3. Statistical results for daytime/ascending surface air temperature and surface skin temperature in July for 14 years of AIRS data.

\begin{tabular}{|c|c|c|c|c|c|c|c|c|}
\hline \multirow[b]{2}{*}{ Year } & \multicolumn{2}{|c|}{ MAD (K) } & \multicolumn{2}{|c|}{ RMSD (K) } & \multicolumn{2}{|c|}{ Minimum (K) } & \multicolumn{2}{|c|}{ Maximum (K) } \\
\hline & $\begin{array}{l}\text { Surface } \\
\text { air temp }\end{array}$ & $\begin{array}{c}\text { Surface } \\
\text { skin temp }\end{array}$ & $\begin{array}{l}\text { Surface } \\
\text { air temp }\end{array}$ & $\begin{array}{c}\text { Surface } \\
\text { skin temp }\end{array}$ & $\begin{array}{l}\text { Surface } \\
\text { air temp }\end{array}$ & $\begin{array}{c}\text { Surface } \\
\text { skin temp }\end{array}$ & $\begin{array}{l}\text { Surface } \\
\text { air temp }\end{array}$ & $\begin{array}{l}\text { Surface } \\
\text { skin temp }\end{array}$ \\
\hline 2003 & 0.1185 & 0.2283 & 0.3114 & 0.6446 & -2.92 & -4.80 & 3.04 & 4.52 \\
\hline 2004 & 0.1165 & 0.2341 & 0.2983 & 0.6467 & -1.94 & -5.18 & 2.68 & 7.76 \\
\hline 2005 & 0.1117 & 0.2306 & 0.3087 & 0.6566 & -1.92 & -5.26 & 2.70 & 5.28 \\
\hline 2006 & 0.1118 & 0.2312 & 0.3515 & 0.7089 & -3.12 & -4.44 & 3.14 & 6.49 \\
\hline 2007 & 0.0936 & 0.2012 & 0.3279 & 0.6694 & -2.31 & -3.26 & 3.55 & 5.18 \\
\hline 2008 & 0.0783 & 0.1899 & 0.3276 & 0.6828 & -3.42 & -4.83 & 2.84 & 4.79 \\
\hline 2009 & 0.1034 & 0.2013 & 0.3078 & 0.6552 & -1.94 & -5.20 & 3.32 & 6.96 \\
\hline 2010 & 0.0839 & 0.2032 & 0.3483 & 0.7078 & -3.68 & -5.06 & 2.80 & 5.30 \\
\hline 2011 & 0.1053 & 0.2119 & 0.3082 & 0.6500 & -2.79 & -5.53 & 3.34 & 4.68 \\
\hline 2012 & 0.1089 & 0.2294 & 0.3118 & 0.6797 & -2.94 & -5.13 & 2.48 & 5.71 \\
\hline 2013 & 0.1130 & 0.2483 & 0.3303 & 0.6937 & -2.12 & -4.10 & 2.62 & 5.88 \\
\hline 2014 & 0.1027 & 0.2404 & 0.3374 & 0.7106 & -2.92 & -4.14 & 2.49 & 6.00 \\
\hline 2015 & 0.0901 & 0.2060 & 0.3540 & 0.7265 & -3.98 & -6.20 & 2.60 & 6.35 \\
\hline 2016 & 0.0894 & 0.2090 & 0.3222 & 0.6866 & -3.44 & -4.36 & 3.79 & 11.85 \\
\hline
\end{tabular}

for both daytime/ascending and nighttime/descending nodes of each month over 14 years.

We also compared the multiyear monthly mean surface air temperature from the AIRS ABO and ABD methods with the climatology product from reanalysis data: the Modern-Era Retrospective Analysis for Research and Applications, version 2 (MERRA-2) dataset. MERRA-2 is the most recent atmospheric reanalysis of the modern satellite era produced by NASA's Global Modeling and Assimilation Office (GMAO) (Gelaro et al. 2017). MERRA-2 addressed many limitations in the original version of MERRA and was introduced to replace the first MERRA data product suite.

The MERRA-2 product has spatial resolution of $0.5^{\circ}$ longitude $\times 0.625^{\circ}$ latitude, which is finer than the $1^{\circ} \times$ $1^{\circ}$ grid of the AIRS Level 3 product. Unlike the separate daytime/ascending and nighttime/descending nodes of the AIRS Level 3 monthly product, the MERRA2 monthly product gives one value in a grid. To compare the 14-yr monthly mean between AIRS and MERRA-2, the daytime/ascending and nighttime/descending values of AIRS are averaged, and the MERRA- 2 data are regridded to coarser resolution of $1^{\circ} \times 1^{\circ}$ from the original $0.5^{\circ}$ longitude $\times 0.625^{\circ}$ latitude.

The netCDF Operators (NCO) toolkit (Zender 2008; $\mathrm{http} / / / \mathrm{nco}$.sourceforge.net/) is a suite of standalone, command line programs, known as operators, and manipulates and analyzes data stored in netCDF accessible formats. Each operator takes netCDF input files, conducts computation and/or variable manipulation, and outputs the resulting netCDF file. We use netCDF Kitchen Sink (ncks) and netCDF Ensemble Averager (ncea) operators to manipulate and average the AIRS 14-yr monthly mean in daytime/ascending and nighttime/descending nodes. For MERRA-2, the 14-yr monthly mean is first generated by using Giovanni's "monthly and seasonal averages" service and then regridded to $1^{\circ} \times 1^{\circ}$ using NCO's netCDF Remapper (ncremap) operator. The conservative regridding algorithm is chosen in the regridding to preserve the integral across the grids.

\section{Differences between two averaging methods}

We first focused on the surface air and skin temperatures to describe the assessment process. In section 4a, we analyze the differences between the surface temperature monthly products from the $\mathrm{ABO}$ and $\mathrm{ABD}$ methods, and then in section $4 \mathrm{~b}$ evaluate the impact of different weighting on the multiyear (here 14-yr) mean of monthly surface temperature, which is often used by the climate research and application communities. In sections $4 \mathrm{c}$ and $4 \mathrm{~d}$, the assessments are conducted for the air temperature at $500 \mathrm{hPa}$ and the water vapor MMR, respectively.

\section{a. Monthly product of surface air and skin temperatures}

We characterize the differences by calculating statistics of two parameters, mean arithmetic difference (MAD) and root-mean-square difference (RMSD). They are defined as

$$
\begin{aligned}
\mathrm{MAD} & =\sum_{i=1}^{N}\left(\mathrm{ABO}_{i}-\mathrm{ABD}_{i}\right) / N, \\
\mathrm{RMSD} & =\sqrt{\sum_{i=1}^{N}\left(\mathrm{ABO}_{i}-\mathrm{ABD}_{i}\right)^{2} / N},
\end{aligned}
$$



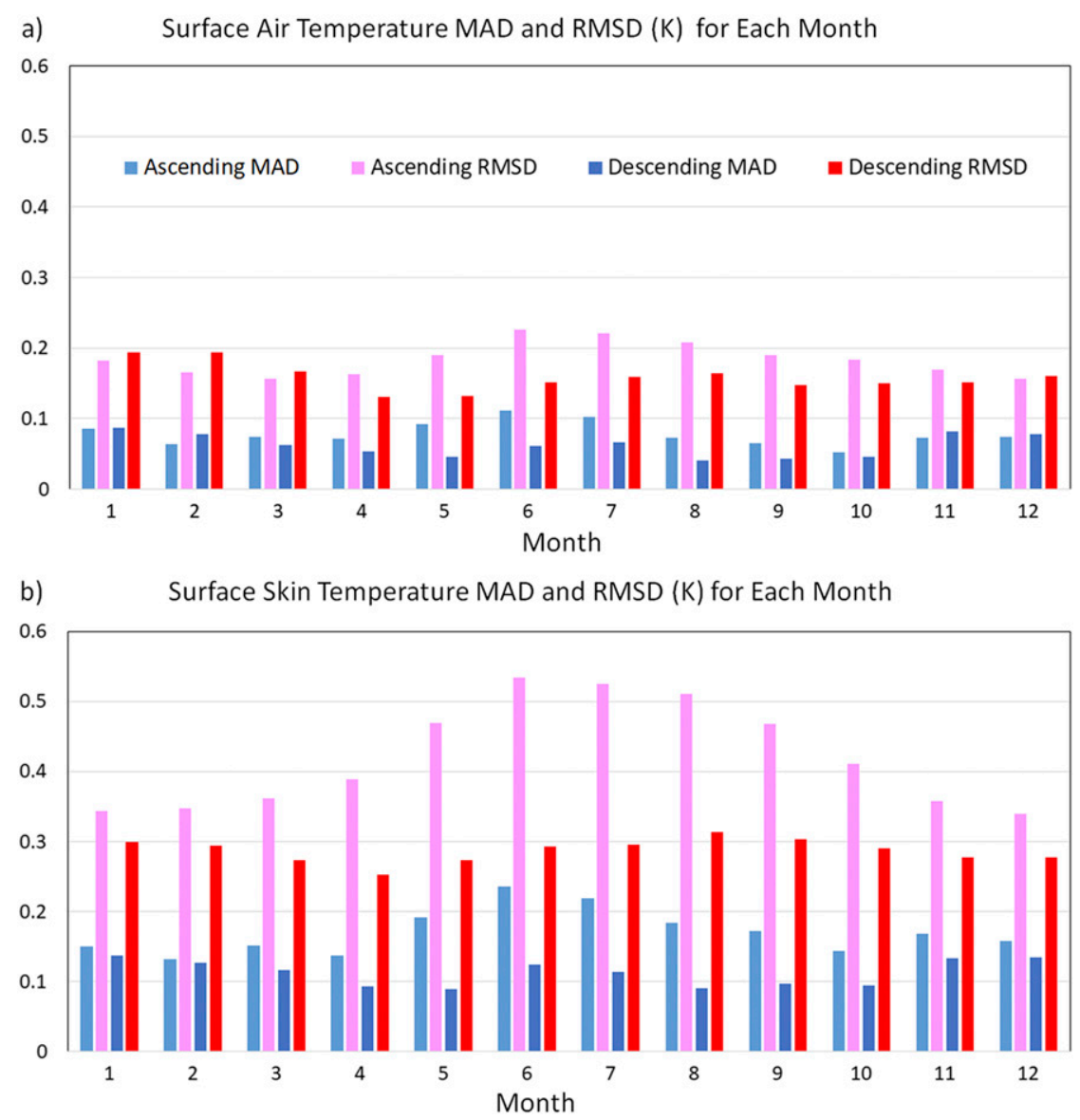

FIG. 5. MAD and RMSD in each month for (a) surface air temperature and (b) surface skin temperature using AIRS data.

where $\mathrm{ABO}_{i}$ and $\mathrm{ABD}_{i}$ are monthly mean value from the $\mathrm{ABO}$ and $\mathrm{ABD}$ method, respectively; $i$ is the index of the sample grid; and $N$ is the total number of sample grids over a region during a period of time. The minimum and maximum values of the difference $\left(\mathrm{ABO}_{i}-\right.$ $\left.\mathrm{ABD}_{i}\right)$ are chosen to represent the extremes.

Table 1 lists the statistics values in an overall comparison for 14 years over the globe. It can be seen that the overall MAD values are all positive, which shows the $\mathrm{ABO}$ averaging method results in a warmer temperature globally. The relatively larger statistics numbers for surface skin temperature show that the surface skin temperature has more variability, and the weighting impact is more significant on the surface skin temperature than on the surface air temperature. This might be explained by the smaller heat capacity of land compared to air. Under extreme situations, the difference can be more than $8 \mathrm{~K}$ for the surface air temperature and $13 \mathrm{~K}$ for the surface skin temperature.

To find the spatial distribution of temperature differences over the globe, we created maps of differences
( $\mathrm{ABO}$ minus $\mathrm{ABD}$ ) of daytime/ascending surface skin and air temperatures in January and July 2006, shown in Figs. 2 and 3, respectively. Year 2006 was chosen as the study case, since there is not a single day with a full day of missing data in this year, and it was neither a strong El Niño year nor a strong La Niña year. January and July represent a winter (summer) and summer (winter) month in the Northern (Southern) Hemisphere.

Both Figs. 2 and 3 show more red and yellow areas (positive) than blue areas (negative), which again demonstrates the warmer global mean temperature from the ABO method than the ABD method. The figures are consistent with the positive MAD numbers in Table 1. A comparison of the difference maps of surface air temperature (Figs. 2a and 3a) with surface skin temperature (Figs. $2 \mathrm{~b}$ and $3 \mathrm{~b}$ ) shows they have very similar distribution patterns, but the surface air temperature maps (Figs. 2a and 3a) show smaller differences than the surface skin temperature maps (Figs. 2b and 3b). This correspondence is also consistent with the statistics numbers in Table 1, that is, 
a) Daytime/Ascending Surface Air Temperature Difference, January of Multi-year Mean

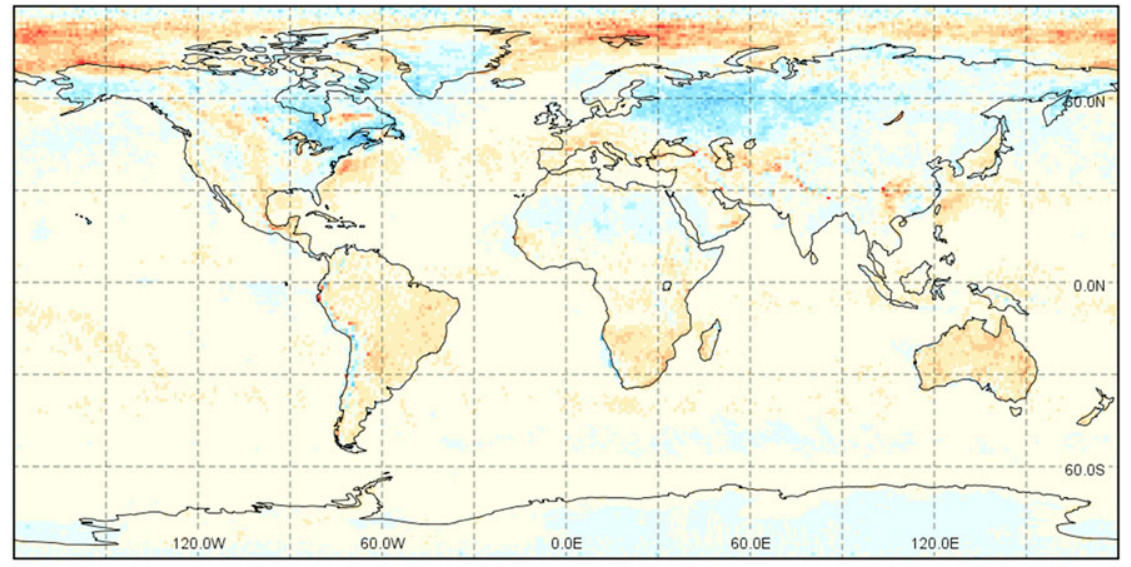

b) Daytime/Ascending Surface Skin Temperature Difference, January of Multi-year Mean

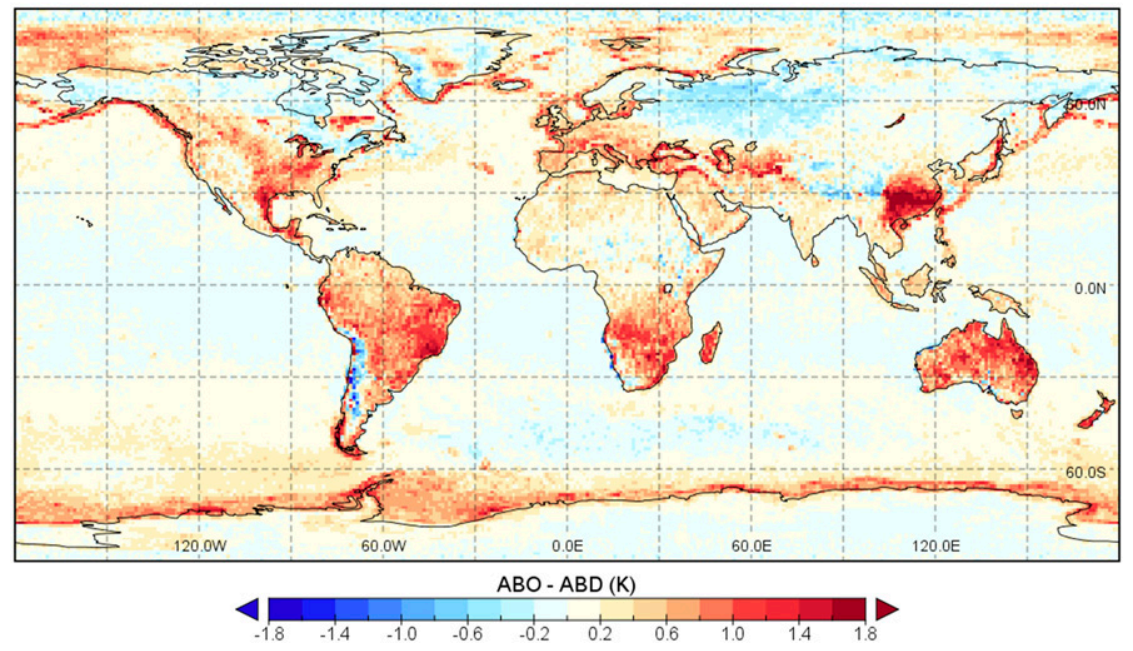

FIG. 6. Maps of difference (ABO - ABD) of daytime/ascending (a) surface air temperature and (b) surface skin temperature for January of multiyear monthly mean using AIRS data.

larger differences for the surface skin temperature than the surface air temperature.

The pattern of positive and negative differences (ABO minus $\mathrm{ABD}$ ) alternates around the globe and varies with region, topography (land or ocean), and season (January or July), which indicates that the dayto-day variations of count numbers due to the combination of the orbit shift and valid retrieval on the monthly means are complex and vary with region and season, even though the ABO method produces a warmer mean temperature globally. The differences are larger over land than over ocean, and also larger in high-latitude areas than in low-latitude areas. It is clear that the $\mathrm{ABO}$ average tends to produce warmer (red and yellow) Southern Hemisphere land surfaces in the austral summer (Fig. 2b), which could be interpreted as an expected cloud radiative effect of cloudy skies and neglecting the retrieval failure scenes in the summer. This is particularly clear in the boreal summer (Fig. 3).

From the definition of monthly $\mathrm{ABO}$ and $\mathrm{ABD}$, their difference is attributed to the day-to-day variations of the count number and retrieval value in a month. If the count number or retrieval value in a grid is same for everyday in a month, there will be no monthly difference between the $\mathrm{ABO}$ and $\mathrm{ABD}$ in this grid for this month. In general, the region with larger difference between $\mathrm{ABO}$ and $\mathrm{ABD}$ is the region with larger day-to-day variations of the count number and the retrieval value.

The daytime/ascending surface air temperature in January 2006 is selected to show the impacts from dayto-day variations of count number and retrieval value. The relative standard deviations of the 31-day total counts (orbital impact) and valid retrieval counts (retrieval yield impact) are calculated and plotted in 
a) Daytime/Ascending Surface Air Temperature Difference, July of Multi-year Mean

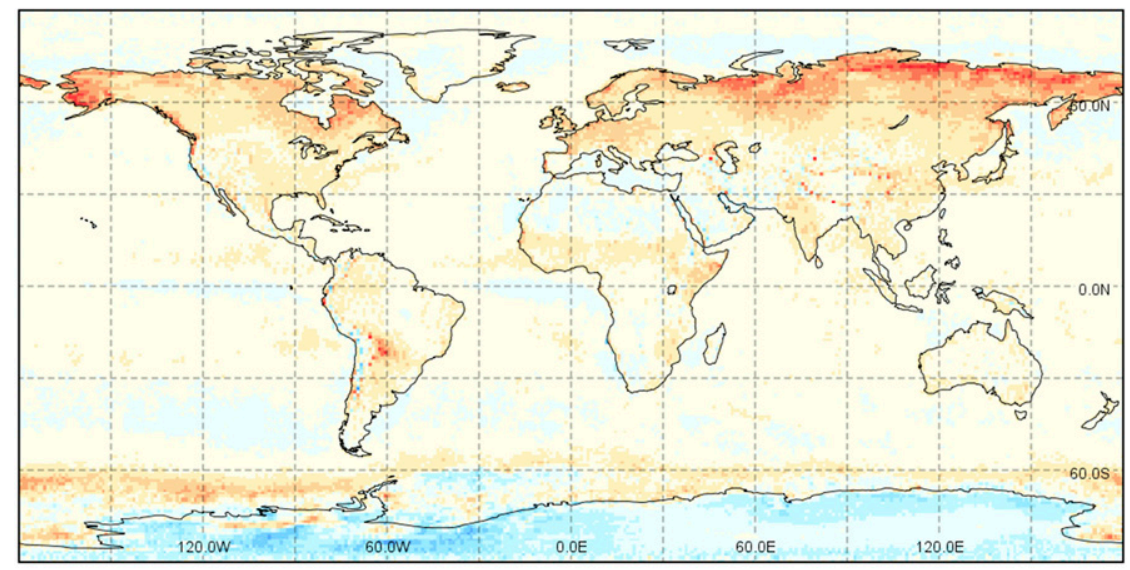

b) Daytime/Ascending Surface Skin Temperature Difference, July of Multi-year Mean

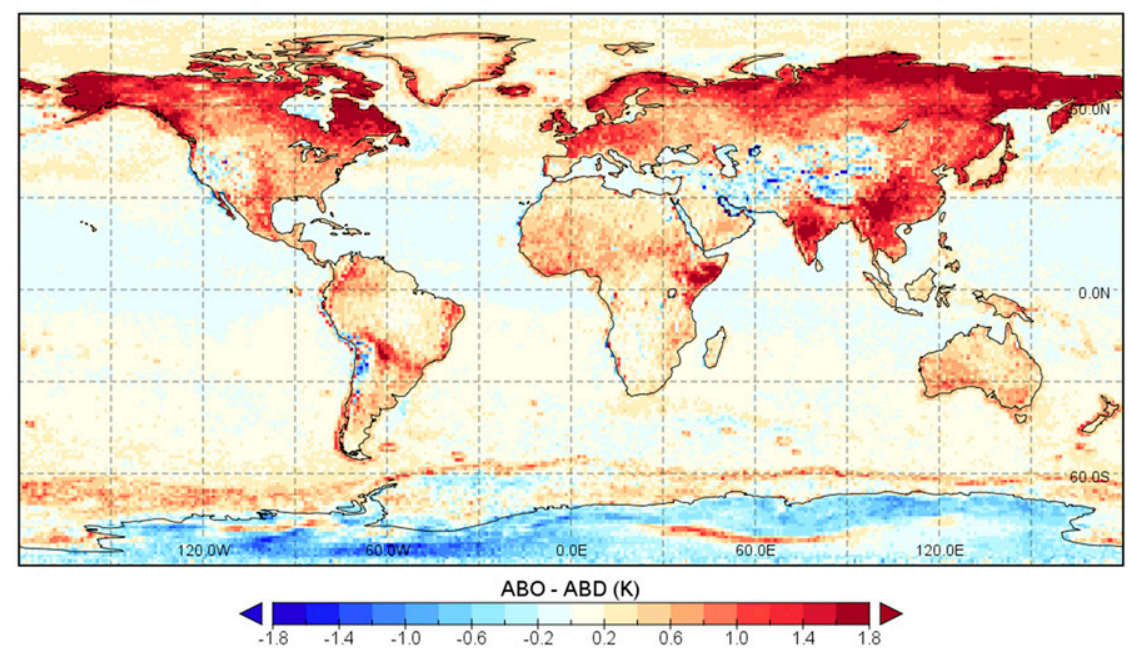

FIG. 7. As in Fig. 6, but for July.

Figs. $4 \mathrm{a}$ and 4b. Here, the relative standard deviation is the ratio of the standard deviation to the mean value. It can be seen that the uniform pattern along longitude due to the day-to-day orbit shift (Fig. 4a) is obviously changed after the retrieval (Fig. 4b). More grids with larger values (red and yellow) in Fig. 4b than in Fig. 4a show that in most regions the counts vary more remarkably from day to day after retrieval than only from orbit shift. This implies the retrieval yield impact to the differences of ABD and ABO methods plays a very important role. Figure $4 \mathrm{c}$ shows the surface air temperature retrieval yield rate mean, where the retrieval yield rate is the ratio of valid count to total count. It can be seen that retrieval is truly in favor of certain weather regimes and topography. The retrievals have relatively high failure rate (lower yield rate) over ice-/snow-covered Northern Hemisphere high latitudes, Northern Hemisphere storm-track regions where it is often cloudy, tropical deep convective regions, and Arctic. The standard deviations of the daytime/ascending surface air temperature are also calculated and plotted in Fig. 4d. The regions with large values in Fig. 4b (count variations) and Fig. 4d (temperature variations) mostly match the regions of large differences (darker blue or red) in Fig. 2a, such as over high-latitude areas in the Northern Hemisphere and Australia.

Cloud radiative effect is complicated and depends on cloud type, height, phase, thickness, and other variables. A cloudy sky does not always cool the surface, but may have a warming effect over high-latitude land during the cold season. This effect is seen from another apparent pattern: the $\mathrm{ABO}$ method tends to produce colder (blue) land surfaces at high latitudes in the hemispheric winter. In January (Fig. 2), the Northern Hemispheric winter, we see large blue areas in the north 
a)

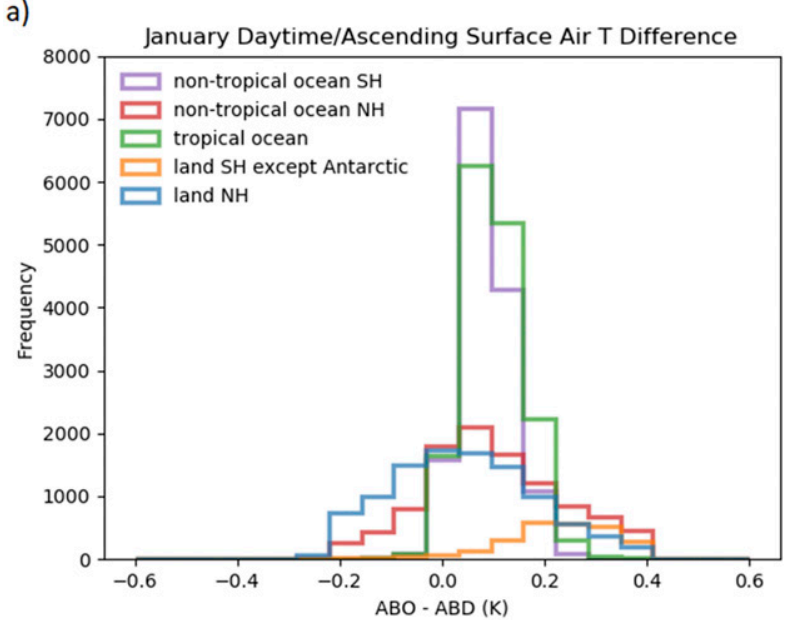

b)

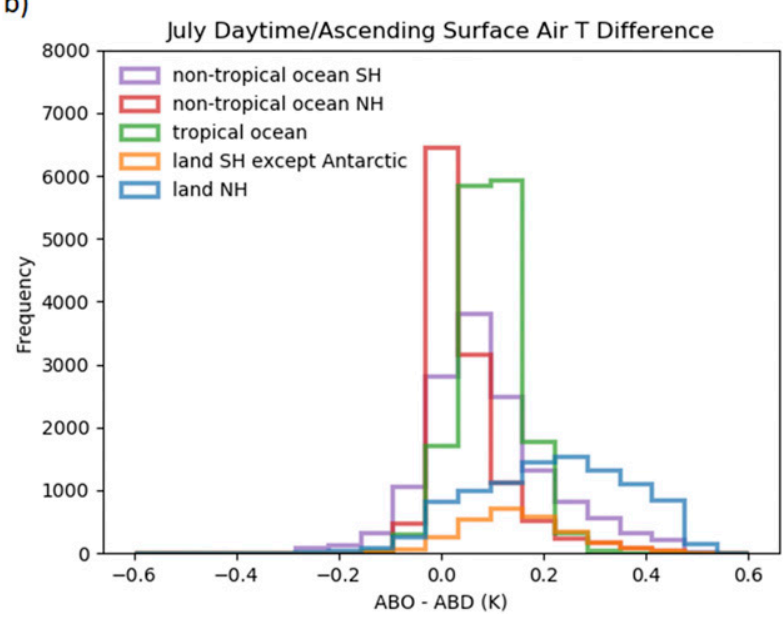

FIG. 8. Histogram of AIRS daytime/ascending surface air temperature difference $(\mathrm{ABO}-\mathrm{ABD}$ ) for (a) January and (b) July using the grids with a confidence level of at least $95 \%$.

polar region, whereas there is wide occurrence of blue areas near the south polar region in July (Fig. 3) when the Southern Hemisphere is in winter. Although not overwhelmingly consistent, this means that over large portions of land areas in the high latitudes of the Northern Hemisphere, the ABO average produces colder estimates. This result is also a potentially desired offset to the ABO method, which apparently favors cooler, clearer-sky winter days.

We calculated the MAD and RMSD for the daytime/ascending surface air and skin temperatures of January and July months over 14 years and listed them in Tables 2 and 3, respectively. It can be seen from month to month and year to year, the statistics numbers vary remarkably. The MADs are positive every year and most MADs are between 0.1 and $0.2 \mathrm{~K}$. The changes of MAD and RMSD in different years for the same month are often about $10 \%-20 \%$. The minimum and maximum values, which represent the extreme cases, show much larger variation even by a factor of 2-3.

Difference maps in other years and months were also examined visually. Difference distribution patterns showed significant variation from year to year and month to month, as supported by the statistics numbers in the Tables 2 and 3. Some variations are quite significant. Therefore, in order to see the impact on long-term data, it is necessary to generate the multiyear monthly means and analyze their differences, which is the focus of the next section.

\section{b. Multiyear monthly mean product of surface air and skin temperatures}

The multiyear monthly mean product is the arithmetic mean of monthly products in the 14-yr period from September 2002 to August 2016. It is representative of a 14-yr climatology, and is generated by averaging the values of each month during the $14-\mathrm{yr}$ period. The average is computed for each $1^{\circ} \times 1^{\circ}$ grid cell, and those years with missing values are excluded from the average. If values for every year are missing at a grid cell, that cell will have a missing value. The multiyear monthly mean products from both $\mathrm{ABO}$ and $\mathrm{ABD}$ methods are created from the corresponding monthly products.

As for the comparison of monthly products, the statistics numbers of MAD and RMSD are calculated for each month from January to December when comparing multiyear monthly mean products from the $\mathrm{ABO}$ and $\mathrm{ABD}$ methods. Figures 5a and 5b illustrate the statistics numbers for the surface air temperature and surface skin temperature.

These figures show that the weighting impact on the monthly products also appears in the multiyear monthly mean products. The differences between the ABO and ABD multiyear monthly mean products are qualitatively similar to those between the ABO and ABD monthly products, but with quantitatively smaller values. The ABO multiyear monthly means are also warmer in each month. Most MADs are between 0.05 and $0.1 \mathrm{~K}$ for surface air temperature and between 0.1 and $0.2 \mathrm{~K}$ for surface skin temperature. The MAD and RMSD numbers show that the surface skin temperature has higher temperature differences than the surface air temperature, which might again be explained by the smaller heat capacity of land compared to air.

Figures $5 \mathrm{a}$ and $5 \mathrm{~b}$ also show that the ascending/daytime MAD is always greater than the descending/nighttime one for surface skin temperature and it is nearly always true for surface air temperature. This reflects that generally larger day-to-day surface temperature variations in daytime than in nighttime may result in the greater ascending/daytime MAD. Therefore, with 


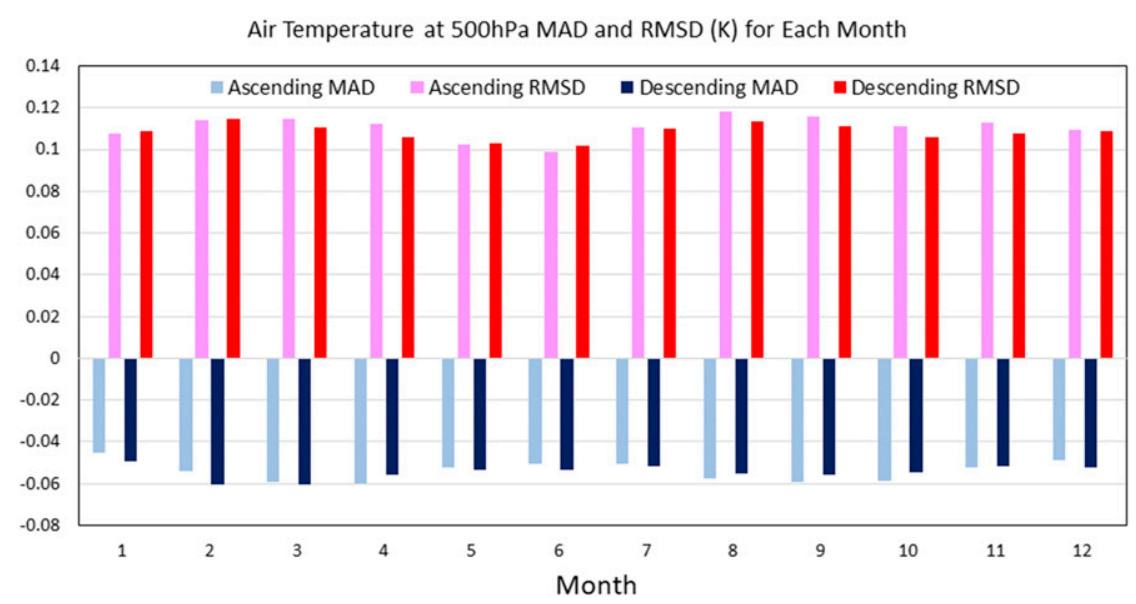

FIG. 9. MAD and RMSD in each month for air temperature at $500 \mathrm{hPa}$ using AIRS data.

larger day-to-day variation, the method of averaging becomes correspondingly more important.

The temperature difference maps ( $\mathrm{ABO}$ minus $\mathrm{ABD}$ ) of the daytime/ascending multiyear January and July monthly means are plotted in Figs. 6 and 7 to generate the spatial distribution of differences over the globe. As in the January and July 2006 monthly difference maps (Figs. 2 and 3), the multiyear monthly mean difference maps (Figs. 6 and 7) also show more positive grids (red and yellow) than negative ones (blue) globally. The absolute values of differences in the multiyear monthly mean (Figs. 6 and 7) are obviously less than those in a single year, 2006 (Figs. 2 and 3). However, there are more positive grids (red and yellow) in the multiyear monthly mean difference maps than the year 2006 difference maps. In addition, the many light yellow and blue alternating stripes in a single year (Figs. 2 and 3), which are mainly from the day-to-day orbit shift impact, are not clearly shown in the multiyear monthly mean (Figs. 6 and 7). This means the day-to-day orbit shift impact to the differences of $\mathrm{ABO}$ and $\mathrm{ABD}$ methods is weaker in the multiyear monthly mean than in a single year, and the impact from the weather regimes with better retrieval skills will dominate the differences in the average over a very long period of time.

In a manner very similar to the January and July 2006 maps (Figs. 2 and 3), the multiyear monthly mean difference maps (Figs. 6 and 7) show negative grids (blue) and positive grids (red and yellow) interspersed and distributed globally. The ABD multiyear monthly mean surface temperatures are warmer near the winter polar regions (July: South Pole; January: North Pole).

To examine whether topography and region affect the difference distribution, the globe was divided into five regions, and histogram plots were generated for January (Fig. 8a) and July (Fig. 8b). The land region is split into
"Land in Northern Hemisphere" and "Land in Southern Hemisphere," but excluding Antarctica to remove the Antarctic icy impact, shown as the blue color and orange color in histogram plots, correspondingly. The ocean region is separated into the "Tropical Ocean," between $30^{\circ} \mathrm{S}$ and $30^{\circ} \mathrm{N}$, and the remainder is then split into the "Non-Tropical Ocean in Northern Hemisphere" and the "Non-Tropical Ocean in Southern Hemisphere," shown with the green, red, and purple colors in Figs. 8a and $8 \mathrm{~b}$, respectively. The histograms only include the grids with temperature difference values within a $95 \%$ confidence interval, which is decided by the mean $\mu$ and the standard deviation $\sigma$ of values. The grids with confidence at least $95 \%$ are those with values between $\mu-1.96 \sigma$ and $\mu+1.96 \sigma$.

In the histogram plots, the overall frequency distribution is clearly skewed toward the positive, consistent with the globally warmer ABO product. The positive grids are mostly from the ocean throughout the year, which can be explained by the radiative effect of cloudy sky over the ocean, and there are many more grids over ocean than over land. The distributions over the Tropical Ocean (green) in January and July are about the same, as there is no obvious seasonal change in the tropical zone. Over the nontropical ocean, there more positive grids in the Southern Hemisphere; that is, there are more higher purple steps than red steps, especially in January (Fig. 8a) when the Southern Hemisphere is warm and the cooling from cloud radiative effect is more significant. The larger ocean area in Southern Hemisphere with respect to the Northern Hemisphere could be the reason for seeing more positive grids over the Non-Tropical Ocean in Southern Hemisphere.

Over Land in Southern Hemisphere except Antarctica (orange), the distributions are positively skewed in both 
a)

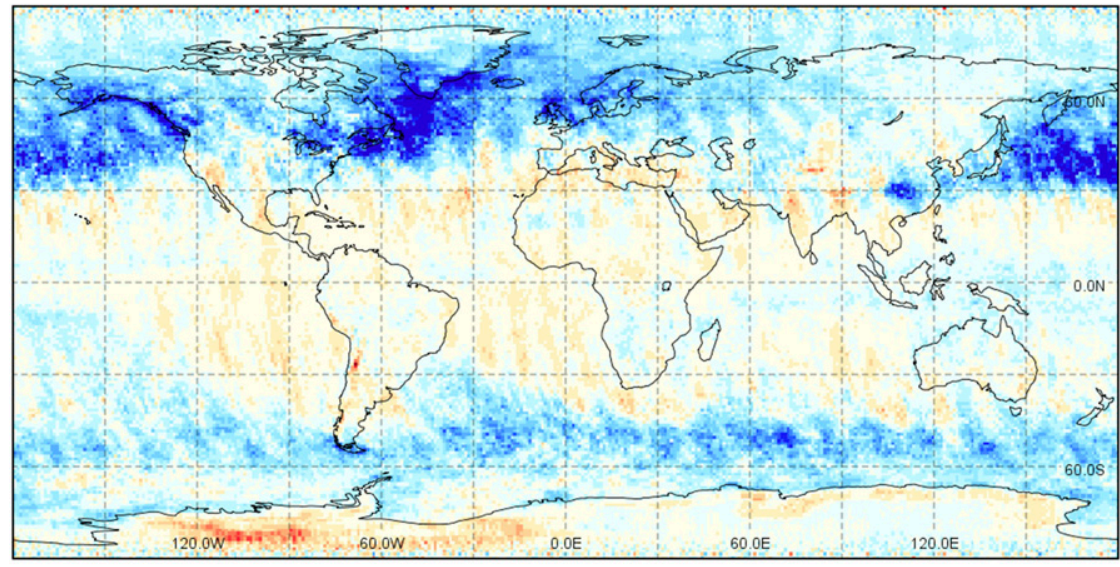

b) Daytime/Ascending $500 \mathrm{hPa}$ Air Temperature Difference, July of Multi-year Mean

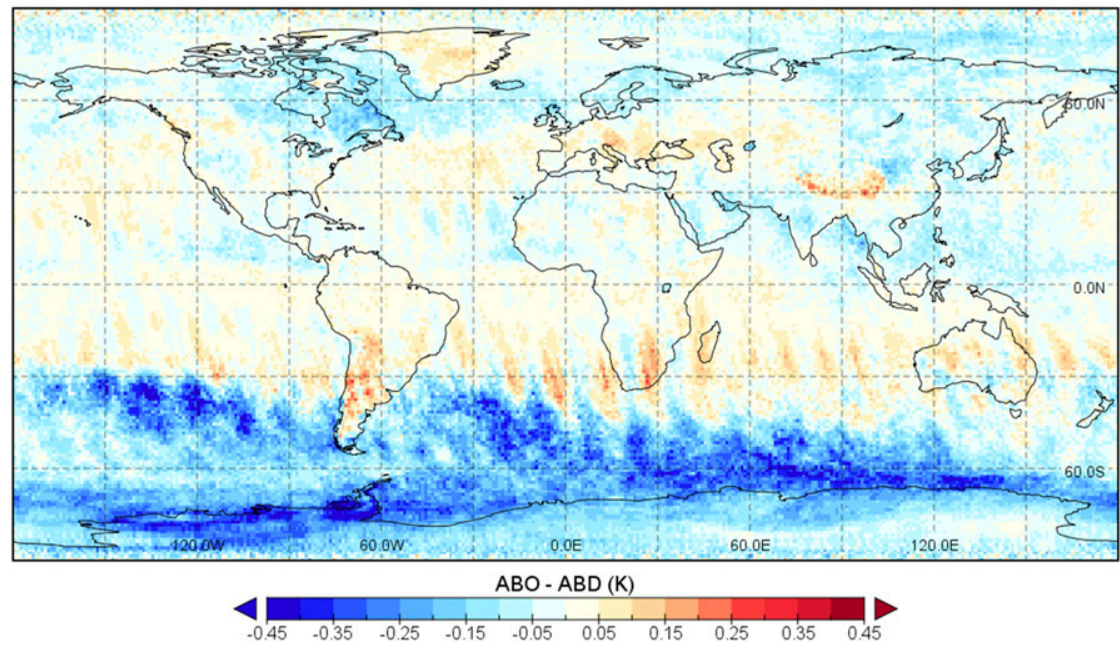

FIG. 10. Maps of difference (ABO - ABD) of daytime/ascending air temperature at $500 \mathrm{hPa}$ for (a) January and (b) July of multiyear monthly mean using AIRS data.

January and July, and skewed further toward positive in January than in July, because of the stronger cooling from cloud radiative effect in the warm season (January) in the Southern Hemisphere. However, over Land in Northern Hemisphere (blue), we see two different scenarios in July and January: a clearly positive distribution in July (Fig. 8b), as over the ocean, and an almost normal distribution in January (Fig. 8a). This shows that the ABO method favoring clear sky days or the cloud radiative effects on the surface temperature are not the same everywhere over Land in Northern Hemisphere in the cold season. In lower-latitude areas, where the surface does not get as cold in the cold season, clouds still cool the surface as expected. When the surface is cold, for example, over high-latitude land in winter, clouds may trap some of the outgoing infrared radiation emitted by the
Earth and radiate it back downward, thereby warming the surface. A cooling from cloud radiative effect is therefore seen over low-latitude land but warming over high-latitude Land in North Hemisphere, as shown in Fig. 6. A nearly normal distribution (blue) in January (Fig. 8a) was incurred as a result of the interspersed warming and cooling of cloud radiative effect over the Land in Northern Hemisphere in the cold season. In the Southern Hemisphere, after excluding the Antarctic, most land regions are in lowerlatitude zones, and thus there are more grids with positive differences where the $\mathrm{ABO}$ method gives overall warmer temperature.

\section{c. Air temperature at $500 \mathrm{hPa}$}

Air temperature at $500 \mathrm{hPa}$ is selected for the assessment to represent the differences of two averaging 

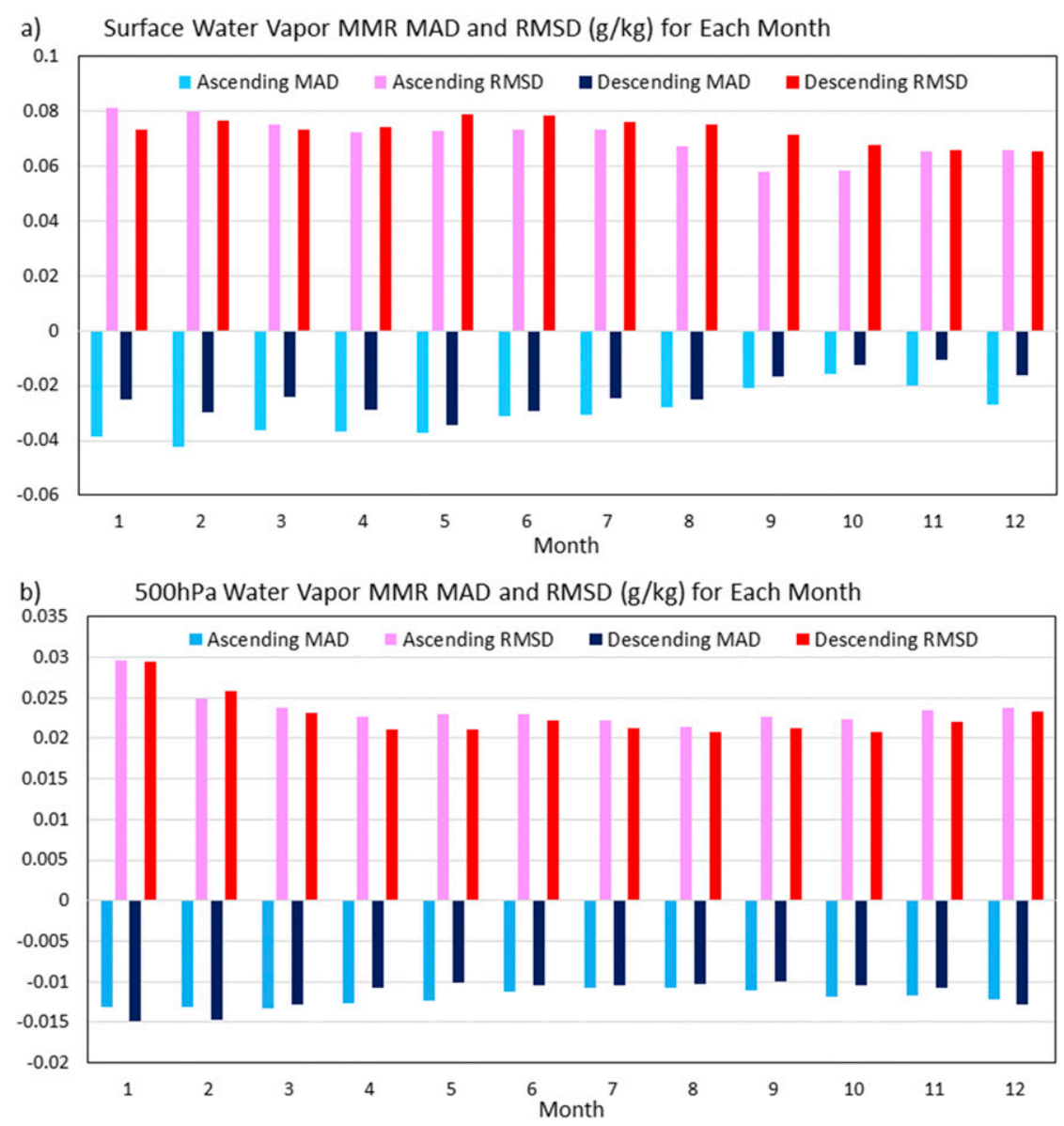

FIG. 11. MAD and RMSD in each month for water vapor mass mixing ratio at (a) the surface and (b) $500 \mathrm{hPa}$ using AIRS data.

methods for the upper-level temperature. The same statistics numbers of MAD and RMSD and difference maps are generated as in the study of the surface temperature. Here, we mainly focus on the results from the multiyear monthly means.

Figure 9 shows the MAD and RMSD numbers for each month from January to December of the multiyear monthly mean. Comparing Fig. 9 to Fig. 5a, we see that, in contrast to the surface air temperature, the MAD numbers are negative, or the temperature at $500 \mathrm{hPa}$ by the $\mathrm{ABO}$ method is globally colder than that by the ABD method. It is also seen that the magnitudes of differences for the $500 \mathrm{hPa}$ temperature are about half of those for the surface air temperature, and the month-tomonth variation of the statistics numbers at the upper level is less than at the surface. These results can be expected as the air temperature at $500 \mathrm{hPa}$ is much colder and has less day-to-day variations than at the surface.

The $500 \mathrm{hPa}$ air temperature difference maps (ABO minus $\mathrm{ABD}$ ) of the daytime/ascending multiyear monthly mean in January and July are plotted in
Fig. 10 to show the spatial distribution of differences over the globe. It is seen that in the low-latitude areas similar alternating-stripes patterns are shown in January (Fig. 10a) and July (Fig. 10b), which indicates that the differences are likely most from the day-to-day orbit shift. In the low-latitude areas, as the retrieval yields are generally higher than high-latitude regions, the day-today orbit shift mainly contributes to the count number variations from day to day. The day-to-day variations of temperature are also small. Hence, the $500 \mathrm{hPa}$ temperature differences between the $\mathrm{ABO}$ and $\mathrm{ABD}$ in the low-latitude areas are mostly caused by the day-to-day orbit shift and shown as alternating-stripes patterns. The larger difference values with dark blue colors are over some high-latitude areas and coincide with the hemispheric winter month-January in the Northern Hemisphere and July in the Southern Hemisphere. We found that the minimum and maximum differences of the extreme cases in most months and years are about -2.5 and $+1.5 \mathrm{~K}$.

Comparing Fig. 10a to Fig. 6a and Fig. 10b to Fig. 7a, we found the difference maps of air temperature at 
a) Daytime/Ascending Surface Water Vapor MMR Relative Difference, January of Multi-year Mean

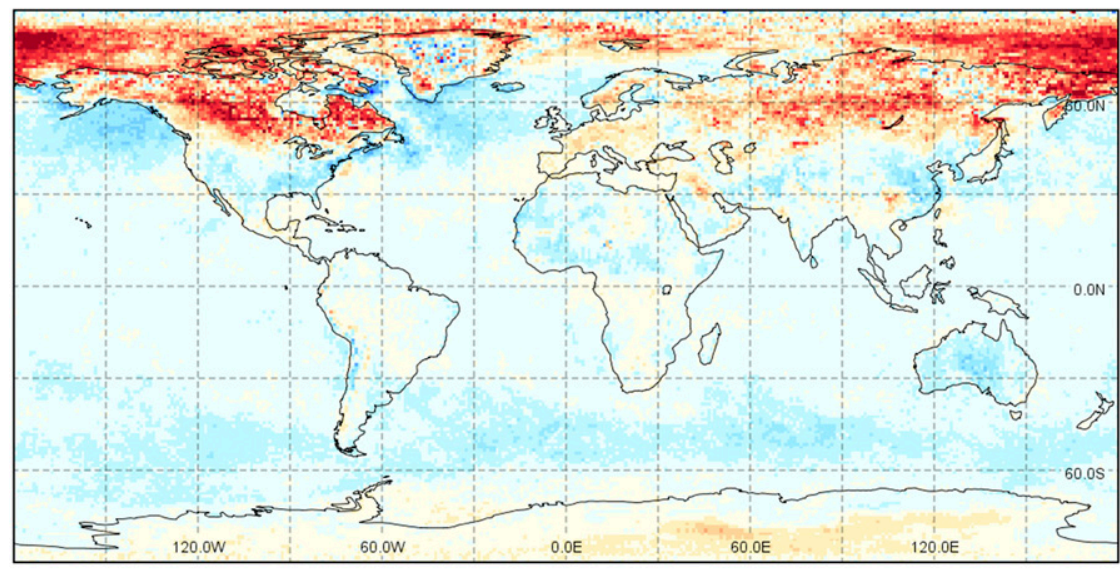

b) Daytime/Ascending Surface Water Vapor MMR Relative Difference, July of Multi-year Mean

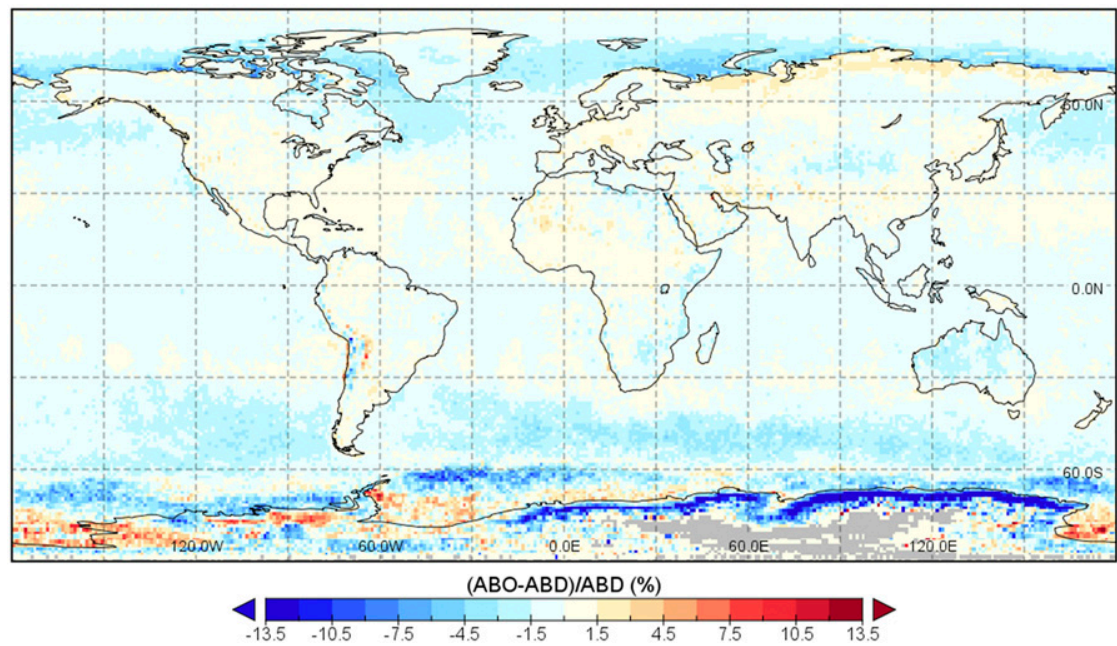

FIG. 12. Maps of relative difference [(ABO - ABD)/ABD] (\%) of daytime/ascending water vapor mass mixing ratio at the surface for (a) January and (b) July of multiyear monthly mean using AIRS data.

$500 \mathrm{hPa}$ show very different spatial distributions from the surface difference maps. In Figs. 6a and 7a, the majority of grids are positive (red and yellow) for the surface air temperature, and the global warmer temperature by the $\mathrm{ABO}$ method can be easily perceived. At $500 \mathrm{hPa}$ (Figs. 10a,b), the numbers of positive (red and yellow) and negative (blue) grids are roughly the same globally. The slightly colder temperature by the $\mathrm{ABO}$ method at $500 \mathrm{hPa}$ over the globe is caused by those grids with very large difference values (dark blue) over some high-latitude areas and coincided with the hemispheric winter month. Those grids are over storm-track regions or southern ocean, where warm air is persistent but the AIRS retrieval has less yields.

\section{d. Water vapor $M M R$}

Water vapor is as essential a retrieval parameter as temperature from AIRS. Water vapor MMRs at the surface and $500 \mathrm{hPa}$ are selected to assess the differences of monthly water vapor from the $\mathrm{ABO}$ and $\mathrm{ABD}$ methods. Like the assessment of temperature, we calculated the statistics numbers of MAD and RMSD to see the global average differences, and plotted the difference maps to show the spatial distribution of differences. The focus is again on the multiyear monthly mean assessment.

Figures $11 \mathrm{a}$ and $11 \mathrm{~b}$ are the bar charts showing the MAD and RMSD numbers for each month from January to December of the multiyear monthly mean of water vapor MMR at the surface and $500 \mathrm{hPa}$, respectively. At both surface and $500 \mathrm{hPa}$ levels, the MAD numbers are negative for each month, which indicates the multiyear monthly mean water vapor from the $\mathrm{ABO}$ method is drier than from the ABD method. This is possibly the impact from the slight retrieval bias for 
a) Daytime/Ascending 500hPa Water Vapor MMR Relative Difference, January of Multi-year Mean

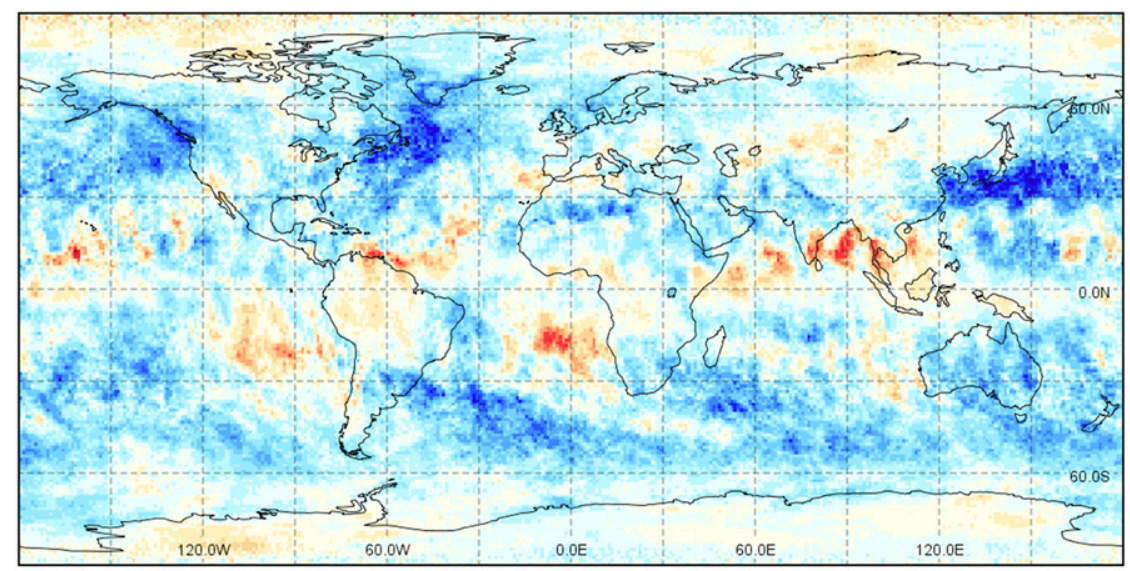

b) Daytime/Ascending 500hPa Water Vapor MMR Relative Difference, July of Multi-year Mean

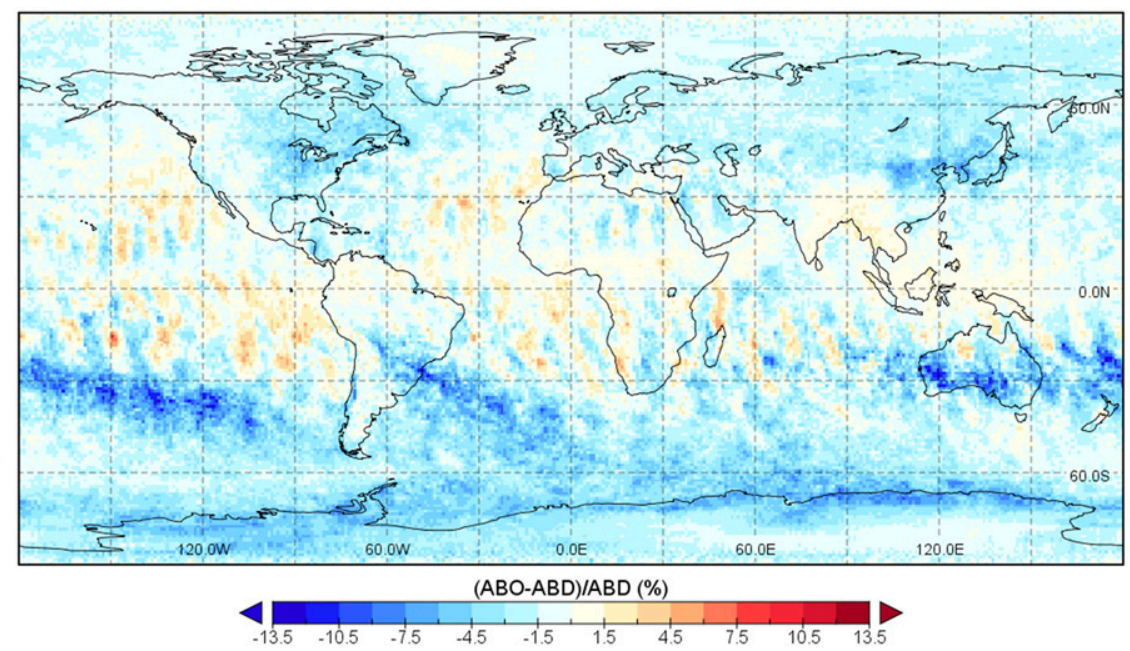

FIG. 13. As in Fig. 12, but for water vapor mass mixing ratio at $500 \mathrm{hPa}$.

clear weather regime, assuming clear days are drier than cloudy days. The much larger RMSD than the MAD means the differences have wide fluctuation.

The water vapor MMR relative difference [ratio of (ABO minus $\mathrm{ABD}$ ) to $\mathrm{ABD}$ ] maps of the daytime/ascending multiyear monthly mean in January and July are plotted in Fig. 12 for the surface level and in Fig. 13 for the $500 \mathrm{hPa}$ level to show the spatial distribution of differences over the globe. As the absolute value change of water vapor MMR is not as easily interpretable as temperature, the relative difference in percentage is used in the difference maps. It is seen that in the lowlatitude areas the alternating stripes patterns appears obvious at $500 \mathrm{hPa}$, which is very similar to temperature (Fig. 10). This serves to indicate that the differences result mostly from the day-to-day orbit shift in lowlatitude areas. The drying effect from the ABO method is stronger (more blue color grids) in the hemisphere's warmer season (January in Southern Hemisphere, July in Northern Hemisphere) and over the ocean, which is essentially attributed to more water vapor in the air in the warmer season and over the ocean. For the extreme cases, the relative differences can be up to $35 \%$ at the surface and $43 \%$ at $500 \mathrm{hPa}$.

\section{Comparison of AIRS ABO and ABD with MERRA-2}

a. Surface air temperature of AIRS versus MERRA-2

The MERRA and MERRA-2 data products provide a long record, beginning in 1980, and have been widely used in climate studies, for example, Coy et al. (2016) and Lim et al. (2017), and even in renewable energy applications (Cannon et al. 2015). Tian et al. (2013a) compared the AIRS product with MERRA for validation, and Hearty et al. (2014) used MERRA data to 

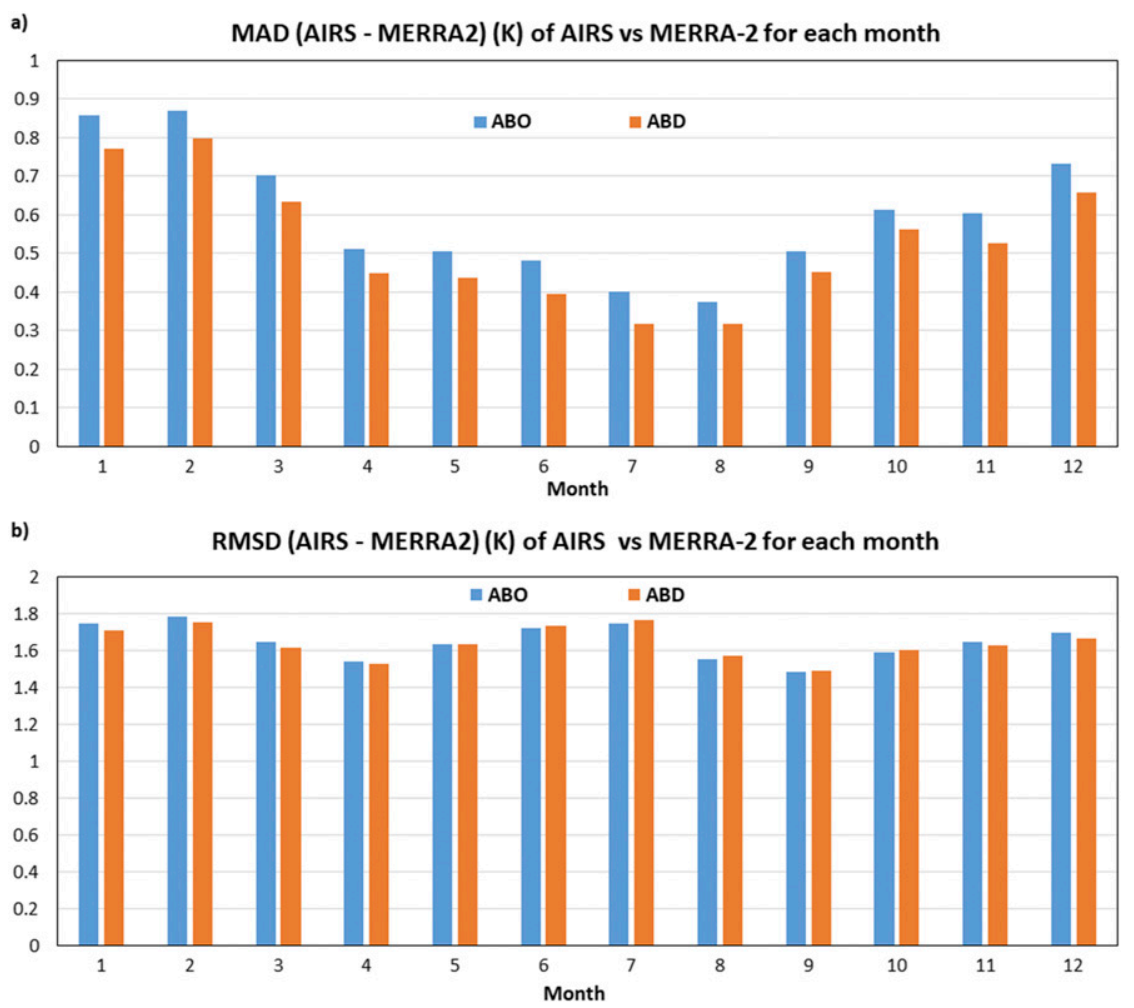

FIG. 14. (a) MAD and (b) RMSD in each month for comparing multiyear surface air temperature mean from AIRS ABO and ABD methods with MERRA-2.

estimate the sampling bias of the AIRS Level 3 product. The AIRS product in the studies of Tian et al. (2013a) and Hearty et al. (2014) is from version 5, and MERRA is the original version. Here, the 14-yr monthly mean of surface air temperature from the AIRS version 6 is compared with MERRA-2. To find the impact of averaging method in the comparison to the reanalysis product, the AIRS 14-yr monthly mean surface air temperatures from both $\mathrm{ABO}$ and $\mathrm{ABD}$ method were compared with MERRA-2.

Similar to the comparison of the $\mathrm{ABO}$ and $\mathrm{ABD}$ multiyear monthly mean product, the statistics of MAD and RMSD are calculated for the AIRS 14-yr monthly mean surface air temperature from the ABO and ABD method with MERRA-2 as reference. The MERRA-2 14-yr monthly mean is first created using Giovanni from the monthly product with the short name M2TMNXFLX (GMAO 2015a), in raw spatial resolution of $0.5^{\circ} \times 0.625^{\circ}$, and then regridded to the same $1^{\circ} \times 1^{\circ}$ resolution as AIRS using NCO's ncremap for quantitative comparison.

Figures $14 \mathrm{a}$ and $14 \mathrm{~b}$ show the MAD and RMSD of each month for the surface air temperature comparison of AIRS versus MERRA-2. The MAD numbers from both $\mathrm{ABO}$ and $\mathrm{ABD}$ methods in Fig. 14a show that AIRS has a warmer 14-yr monthly mean surface air temperature for each month when comparing with MERRA-2 globally, whereas January and February have the largest differences, from about 0.75 to $0.85 \mathrm{~K}$, and July and August show the lowest values, about 0.3 to $0.4 \mathrm{~K}$. Since the multiyear monthly mean from the AIRS ABO method is warmer than that from the ABD method, we see that the blue bar $(A B O)$ is higher than the orange bar (ABD) for each month in Fig. 14a. Note, however, that the differences between the blue and orange bars $(0.05-0.1 \mathrm{~K})$ are much less than the bar heights themselves $(0.3-0.9 \mathrm{~K})$. These comparisons show that the essential differences between the model and satellite observations (represented by bar heights) are much larger than the differences from two averaging methods (represented by blue and orange bar height differences). Some of these differences may be due to the sampling biases of the AIRS data (Hearty et al. 2014). In Fig. 14b, the RMSD numbers are from about 1.5 to $1.8 \mathrm{~K}$, which are much larger than the MAD numbers, but do not change remarkably from month to month and season to season as for MAD shown in Fig. 14a. The relatively larger RMSD for MAD indicates that the difference data values are spread out over a wide range. 
a) (Simulated ABD - MERRA2) for Surface Air Temperature (K), January 2006

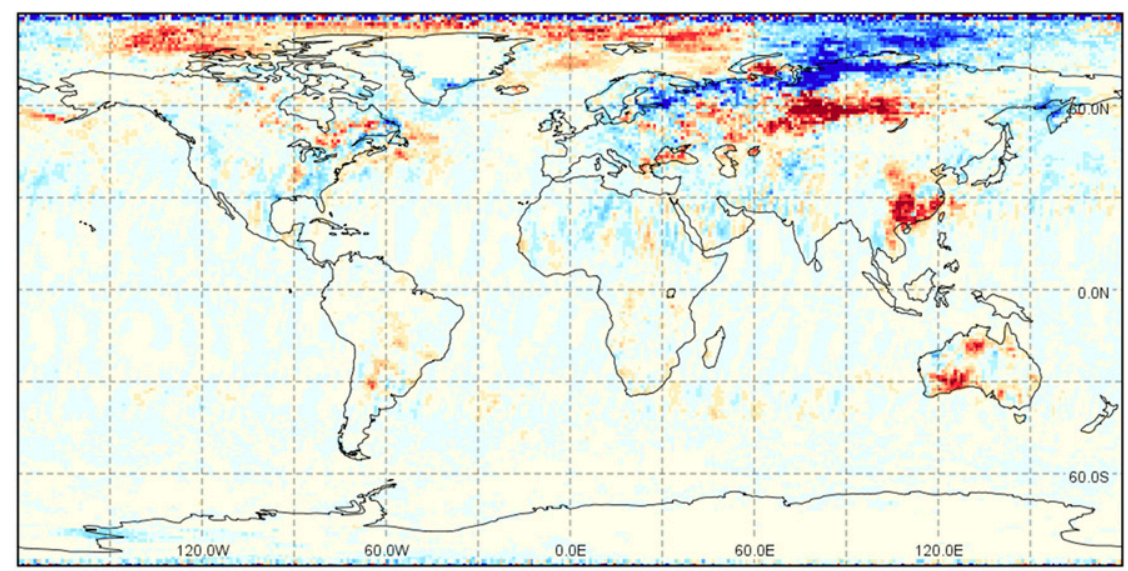

b) (Simulated ABO - MERRA2) for Surface Air Temperature (K), January 2006

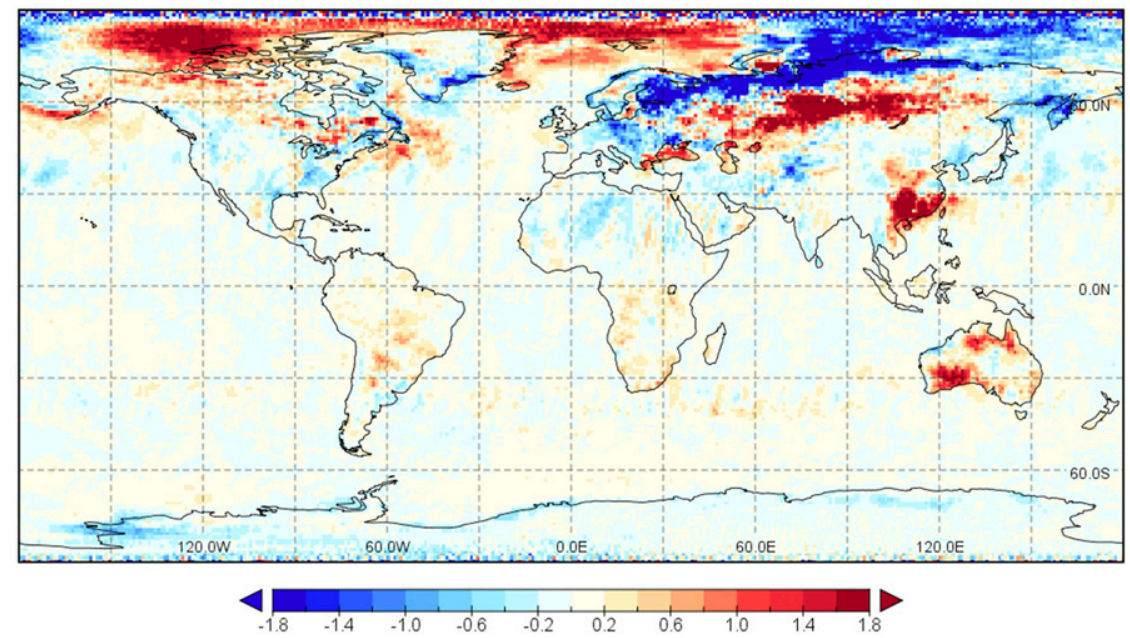

FIG. 15. Error maps of (a) simulated ABD and (b) simulated ABO with regard to MERRA-2 for surface air temperature in January 2006.

Studies comparing AIRS version 5 with MERRA (Tian et al. 2013a; Hearty et al. 2014) find the near surface temperature from MERRA is colder than that from the AIRS. We see this result still stands with the comparison of the AIRS version 6 versus MERRA-2.

\section{b. Simulation experiment}

To avoid the impact of the large essential differences between the MERRA-2 and AIRS retrieval, a simulation experiment is conducted for a better comparison of the $\mathrm{ABO}$ and $\mathrm{ABD}$ with the reanalysis product. In the simulation, AIRS monthly ABO and ABD are generated from AIRS and MERRA-2 daily products by using AIRS count numbers but replacing the AIRS retrieved values with MERRA-2 values from products with short names M2SDNXSLV (GMAO 2015b), M2I1NXASM (GMAO 2015c), and M2I3NPASM (GMAO 2015d).
It eliminates the impact from the bias between AIRS retrieval and MERRA-2 but keeps the day-to-day variations of count numbers in AIRS retrieval and of variables in MERRA-2. Therefore, MERRA-2 can be referred as "truth" when comparing with the simulated AIRS ABO and ABD, and the "difference" between simulated $\mathrm{ABO}$ and $\mathrm{ABD}$ with MERRA-2 can be called "error."

The error maps of simulated monthly $\mathrm{ABO}$ and $\mathrm{ABD}$ with regard to MERRA-2 for surface air temperature in January and July 2006 are shown in Figs. 15 and 16, respectively. They show that in both months the error distribution of simulated $\mathrm{ABO}$ and $\mathrm{ABD}$ have very similar patterns, but $\mathrm{ABO}$ has larger errors (darker colors). Errors over the land are larger than over the sea, and regions with larger errors are in consistent with the hemisphere in the winter month (January in 
a)

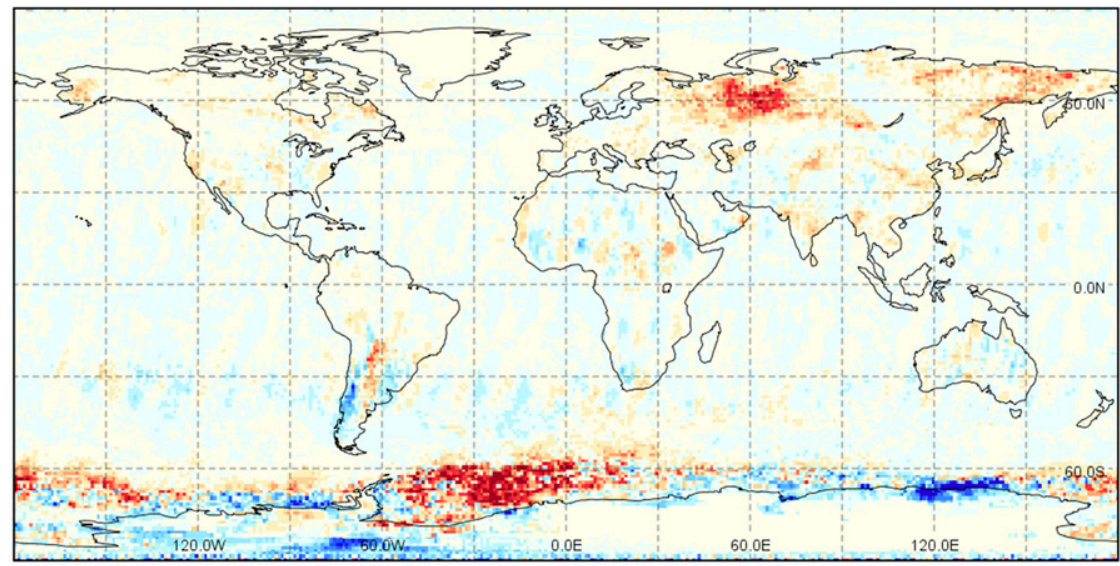

b)

(Simulated ABO - MERRA2) for Surface Air Temperature (K), July 2006

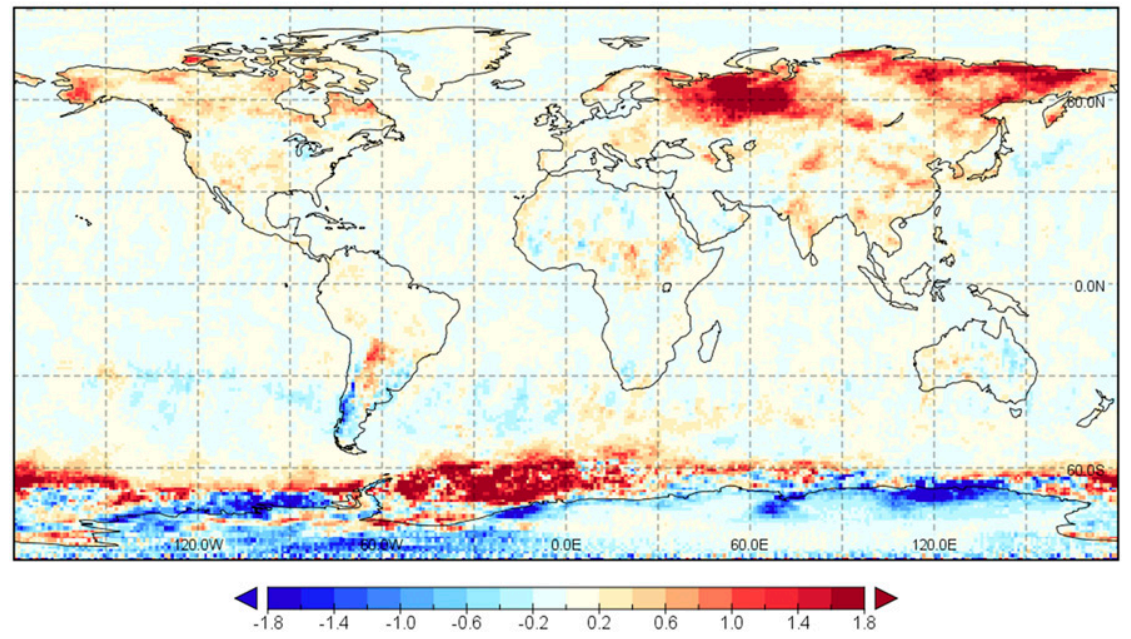

FIG. 16. As in Fig. 15, but for July 2006.

the Northern Hemisphere and July in the Southern Hemisphere).

Mean absolute error (MAE) and root-mean-square error (RMSE) of simulated ABO and ABD are calculated for multiyear monthly mean surface air temperature in each month and shown in Fig. 17. The solid lines represent the errors for simulated $\mathrm{ABD}$ and dashed lines for simulated ABO. The errors over all grids in the globe (black), over the land (green), and over the sea (blue) are calculated and shown separately. The impact only by orbit shift is also simulated by using the total count numbers and shown in the red color.

From Fig. 17, we can see the errors by orbit shift are much less than those due to the retrieval yield. The red solid and dashed lines are very close and nearly overlaid on each other. This serves to prove that over long time periods, the $\mathrm{ABO}$ and $\mathrm{ABD}$ differences from the orbit shift impact are nearly negligible for the surface air temperature. With the retrieval accounted for, the errors by $\mathrm{ABO}$ are much larger than those by $\mathrm{ABD}$ method. It is seen that $\mathrm{ABO}$ errors (dashed line) are even double the corresponding ABD errors (solid line) in some months. The errors over the sea (blue) are much smaller than over the land (green), only about half or even one-third in some months. The errors over the sea are not only smaller but also vary much less from month to month than over the land. The RMSE is about twice of MAE in many months, which indicates the errors spread over a wider range than error values themselves.

The simulation experiments are also conducted for multiyear mean air temperature at $500 \mathrm{hPa}$ and specific humidity, representing water vapor, at the surface and $500 \mathrm{hPa}$. The error comparisons for surface specific humidity in January and July are shown as a bar chart in Fig. 18. The relative MAE and RMSE are used for the specific humidity comparison, which makes the results easier 
a) MAE (K) of Surface Air Temperature for Each Month

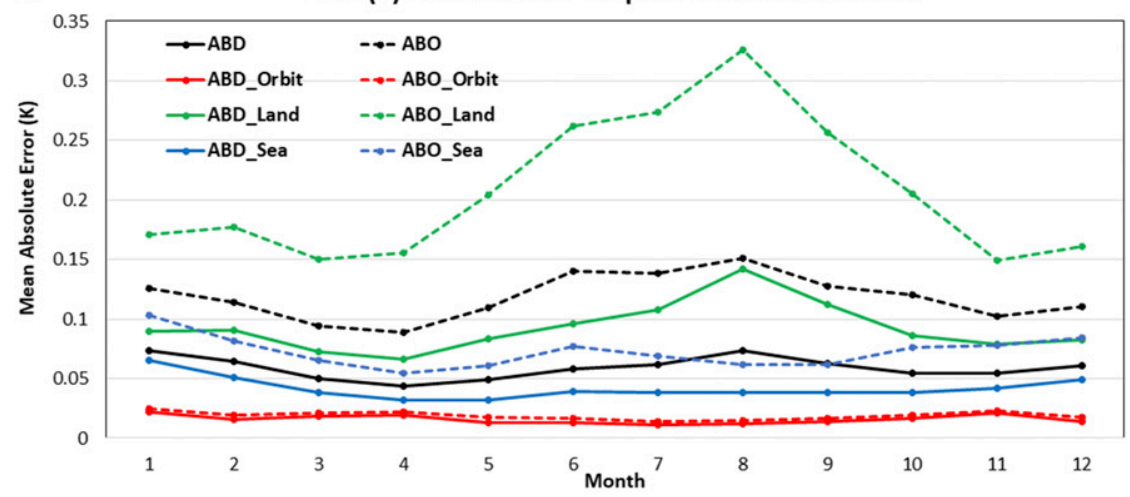

b)

RMSE (K) of Surface Air Temperature for Each Month

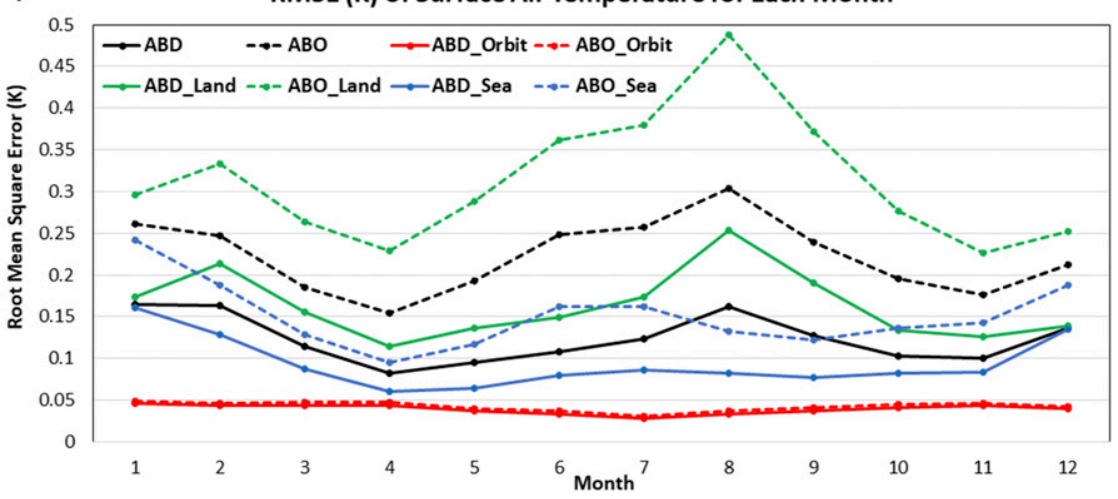

FIG. 17. (a) MAE and (b) RMSE in each month for comparing the multiyear surface air temperature mean from simulated AIRS ABO and ABD methods with MERRA-2.

to interpret. The bar in solid color is for $\mathrm{ABD}$, and the pattern-filled bar is for ABO. For surface specific humidity, we also see the ABO method has larger error than the ABD method but smaller error differences compared with surface air temperature. The errors over the land are about 5 times larger than over the sea, and the errors from only the orbit impact are also very small compared with the impact from the retrieval yield.

The error comparisons for the temperature and specific humidity at $500 \mathrm{hPa}$ in January and July are shown

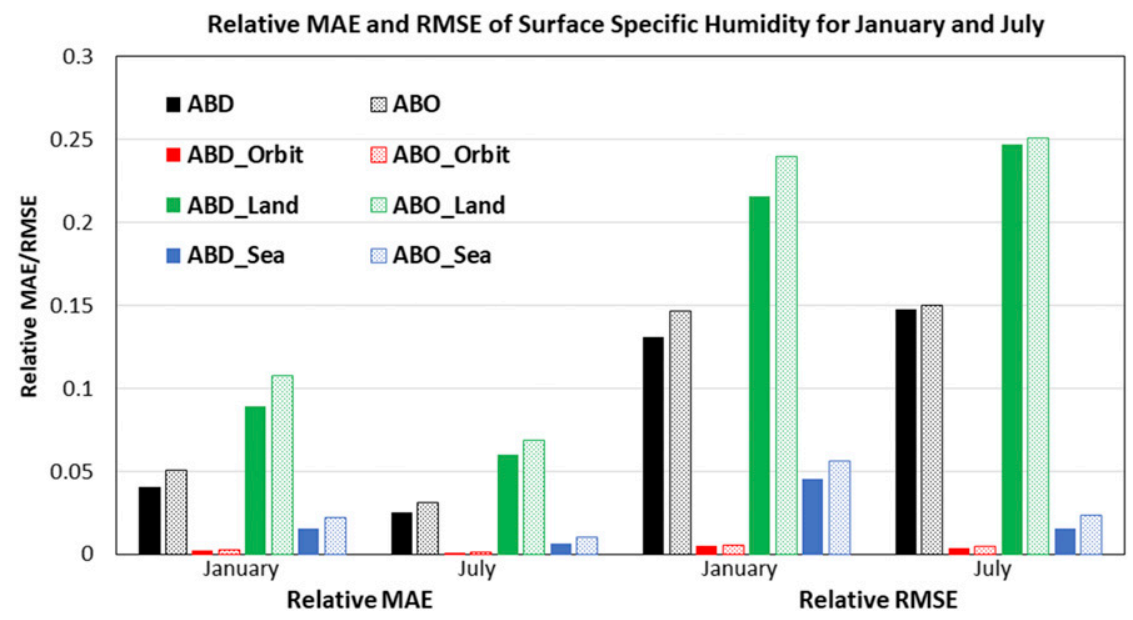

FIG. 18. Relative MAE and RMSE of surface specific humidity for the multiyear January and July monthly means from simulated AIRS ABO and ABD methods compared with MERRA-2. 

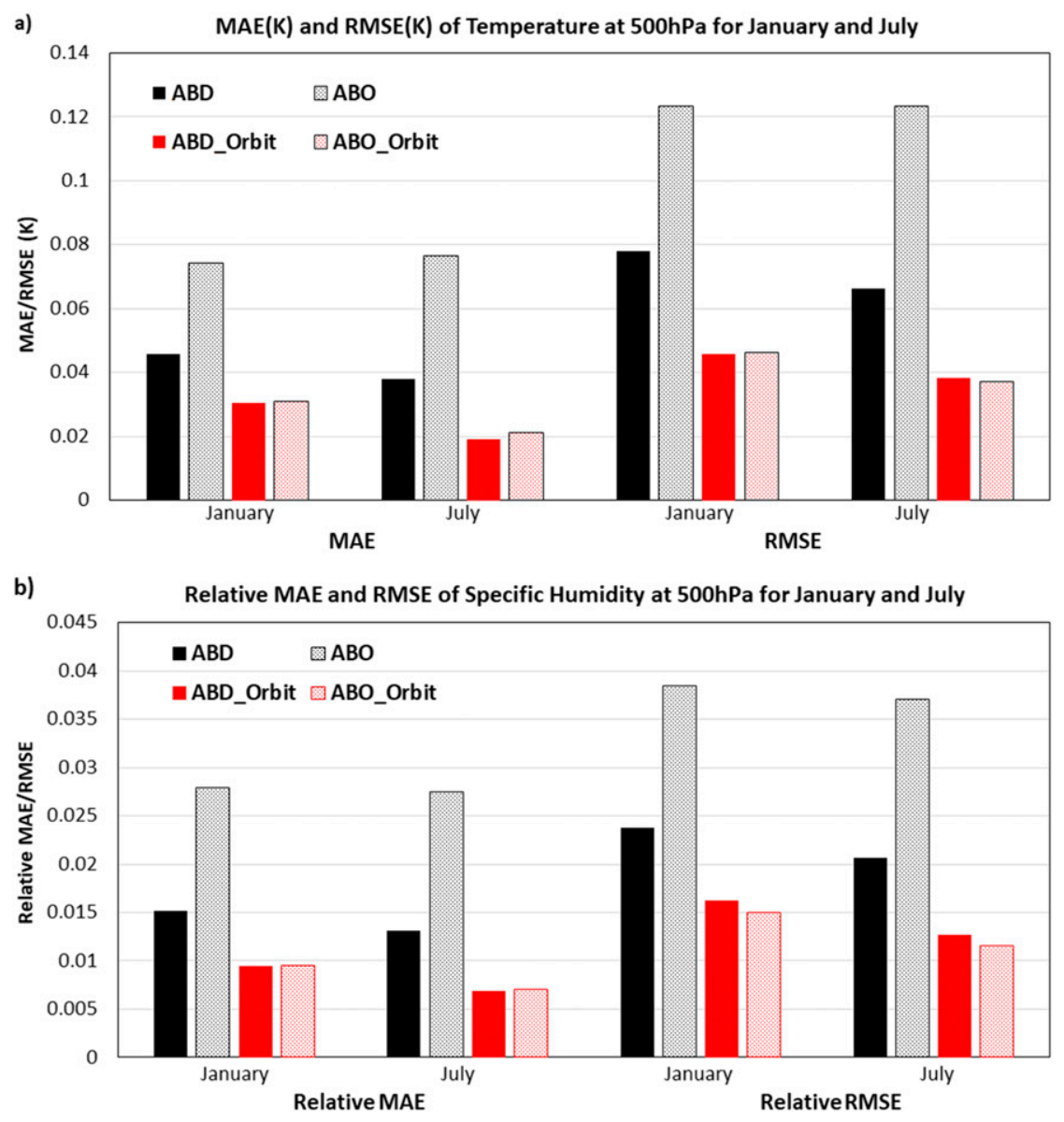

FIG. 19. (a) MAE and RMSE of air temperature and (b) relative MAE and RMSE of specific humidity at $500 \mathrm{hPa}$ for the multiyear January and July monthly means from simulated AIRS $\mathrm{ABO}$ and $\mathrm{ABD}$ methods compared with MERRA-2.

in Fig. 19. From Fig. 19 we see that the errors at $500 \mathrm{hPa}$ by $\mathrm{ABO}$ method are also much larger than by $\mathrm{ABD}$ method for both temperature and specific humidity. However, there are a few new findings at this upper atmospheric level. First, different from at the surface, where the error over the land are much larger than over the sea, the errors at $500 \mathrm{hPa}$ over the land and over the sea are about the same and hence are not shown. Second, errors in different months (January and July) are also nearly same at $500 \mathrm{hPa}$, whereas at the surface the differences between January and July are more obvious. This can be explained by the relative larger dayto-day variations from month to month and from sea to land at the surface than at $500 \mathrm{hPa}$ level. Finally, we see that although at $500 \mathrm{hPa}$ the errors from only the orbit impact are smaller than from the retrieval yield, they are not small enough to be ignored, as is the case at the surface. This is consistent with the difference spatial distribution maps of Figs. 10 and 13, where more obvious alternative stripe patterns shown at $500 \mathrm{hPa}$ level.
Reanalysis and satellite data have been used for the study of temperature variations and trends (Simmons et al. 2017; Susskind et al. 2019). Therefore, we also assess the differences of two AIRS averages in the 14-yr temperature trends study with respect to MERRA-2. To avoid the selection from many statistical trend estimation methods (Mudelsee 2019), linear correlation coefficients between the simulated $\mathrm{ABO}$ and $\mathrm{ABD}$ with MERRA-2 over 14-yr are calculated at each gird for the assessment. The averaging method with closer correlation to MERRA-2 can be expected to have more consistent trend estimation with MERRA-2.

Figures $20 \mathrm{a}$ and $20 \mathrm{~b}$ are the correlation coefficient difference maps of two simulated AIRS averages with MERRA-2 (ABD minus ABO) in January and July, respectively. It can be seen that the ABD method has closer correlation with MERRA-2 at many more grids (more yellow and red colors grids) globally. We also found that more correlation coefficient improvements are over higher latitudes than over lower latitudes. 


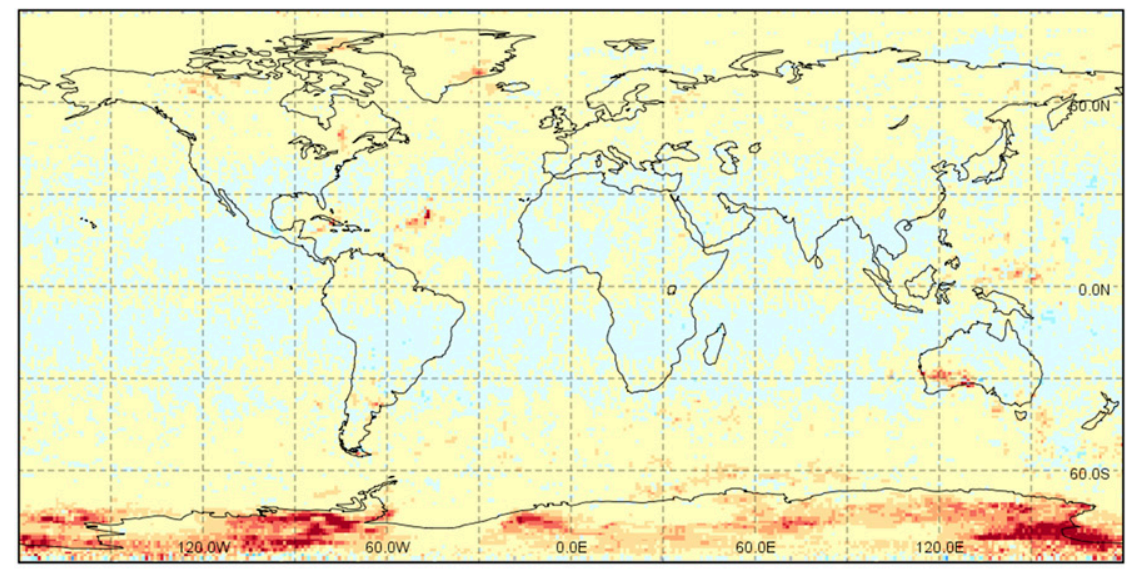

b) Simulated AIRS vs MERRA-2 Correlation Coefficient Difference (ABD-ABO), July

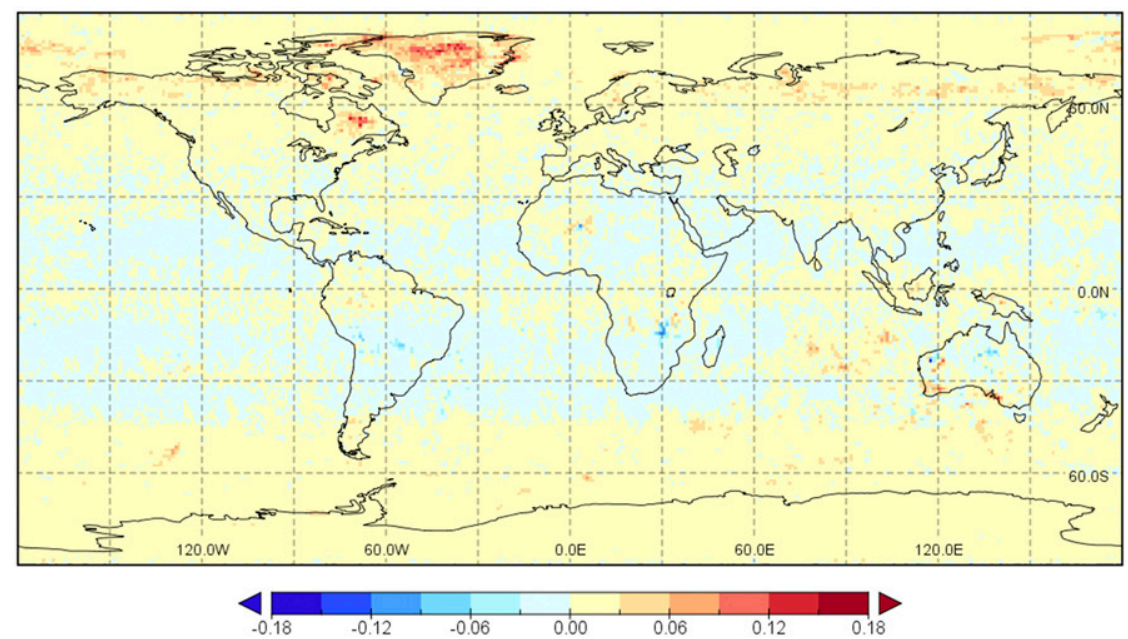

FIG. 20. Correlation coefficient difference maps (ABD - ABO) of simulated AIRS surface air temperature with MERRA-2 for (a) January and (b) July.

The evaluation results from the simulation experiment for the air temperature and water vapor at the surface and upper level clearly prove that the ABD method has less error than the $\mathrm{ABO}$ method and is more closely correlated with the reanalysis for the climate variation and trend study. Note, in this experiment the MERRA-2 product is used for only simulating the day-to-day variations of temperature and water vapor. Therefore, the same conclusion can be expected by using other reanalysis products as long as the day-to-day variations of temperature and water vapor in other reanalysis products are similar to those in MERRA-2.

\section{Summary and recommendation for the future AIRS Level 3 product and data services}

Global gridded AIRS Level 3 monthly products are often used in long-term and large-scale weather and climate studies. In this study, the differences from two averaging methods, the $\mathrm{ABO}$ and $\mathrm{ABD}$ methods, are investigated quantitatively using the temperature and water vapor at the surface and $500 \mathrm{hPa}$ in the AIRS version 6 product. The assessments are conducted for the 14-yr period, and for the monthly product in a single year and the 14-yr mean. The differences between the ABO and $\mathrm{ABD}$ methods are due to the combination of satellite day-to-day orbit shift and the valid retrieval counts slight bias toward regimes with better retrieval skills. The AIRS standard monthly product, created using the ABO method, produces a warmer (slightly colder) global mean temperature at the surface $(500 \mathrm{hPa})$, and a drier global water vapor. The differences are more significant at the surface than the upper level, and more significant for temperature than water vapor. The impact from the slight retrieval bias toward regimes with better retrieval skills is greater in the multiyear monthly mean than in a single-year monthly product. 
The AIRS 14-yr monthly mean surface air temperatures resulting from the $\mathrm{ABO}$ and $\mathrm{ABD}$ methods were also compared with the model reanalysis product MERRA-2. This comparison determined that AIRS temperatures were warmer than MERRA-2 temperatures globally, and the warmer AIRS temperature with respect to MERRA-2 is mainly attributed to the essential differences of modeling versus satellite observation. To eliminate such essential differences between AIRS retrieval and reanalysis, a simulation experiment is conducted by using AIRS count numbers but replacing the AIRS retrieved value with MERRA-2. The evaluation results from the simulation experiment for the air temperature and water vapor at the surface and upper level clearly prove that the $\mathrm{ABD}$ method has less error than the ABO method. The simulated surface air temperature monthly mean by the ABD method is also more closely correlated with MERRA-2 than the $\mathrm{ABO}$ method, which implies that the temperature variations and trends analysis from the ABD method should have better agreement with reanalysis.

This study may serve as one guideline for future Level 3 product generation with AIRS and other satellite sounders. We recommend the ABD method for adoption by the next generation of the future version of the AIRS Level 3 product, likely seen as the AIRS version 7 and subsequent. It must also be admitted that there is no agreement in the satellite data product community whether the Level 2 or Level 3 averaging method is the best. Users may generate the Level 3 monthly product in different ways by themselves for their specific applications. Therefore, in order to support such needs, developing more data services to facilitate the Level 2 to Level 3 aggregation are recommended for NASA GES DISC.

Acknowledgments. We would like to acknowledge Elaine Keim, NASA intern from Texas Tech University, who produced monthly products of ABD method using Giovanni, and Dr. Jim Acker for his editorial revision work to improve the manuscript. Part of this research was carried out at the Jet Propulsion Laboratory, California Institute of Technology, under a contract with the National Aeronautics and Space Administration.

\section{REFERENCES}

Acker, J. G., and G. Leptoukh, 2007: Online analysis enhance NASA Earth science data. Eos, Trans. Amer. Geophys. Union, 88, 14-17, https://doi.org/10.1029/2007EO020003.

AIRS Science Team/Joao Teixeira, 2013a: AIRS/Aqua L3 monthly standard physical retrieval (AIRS + AMSU) 1 degree $X$ 1 degree V006. Goddard Earth Sciences Data and Information Services Center (GES DISC), accessed August 2017, https:// doi.org/10.5067/Aqua/AIRS/DATA319.
— 2013b: AIRS/Aqua L3 Daily Standard Physical Retrieval (AIRS + AMSU) 1 degree $\times 1$ degree V006. Goddard Earth Sciences Data and Information Services Center (GES DISC), accessed August 2017, https://doi.org/10.5067/Aqua/AIRS/ DATA301.

Aumann, H. H., and Coauthors, 2003: AIRS/AMSU/HSB on the Aqua mission: Design, science objectives, data products, and processing systems. IEEE Trans. Geosci. Remote Sens., 41, 253-264, https://doi.org/10.1109/TGRS.2002.808356.

Cannon, D. J., D. J. Brayshaw, J. Methven, P. J. Coker, and D. Lenaghan, 2015: Using reanalysis data to quantify extreme wind power generation statistics: A 33 year case study in Great Britain. Renewable Energy, 75, 767-778, https://doi.org/10.1016/ j.renene.2014.10.024.

Chahine, M. T., and Coauthors, 2006: AIRS: Improving weather forecasting and providing new data on greenhouse gases. Bull. Amer. Meteor. Soc., 87, 911-926, https://doi.org/10.1175/BAMS-87-7-911.

Coy, L., K. Wargan, A. M. Molod, W. R. McCarty, and S. Pawson, 2016: Structure and dynamics of the quasi-biennial oscillation in MERRA-2. J. Climate, 29, 5339-5354, https://doi.org/ 10.1175/JCLI-D-15-0809.1.

Gelaro, R., and Coauthors, 2017: The Modern-Era Retrospective Analysis for Research and Applications, version 2 (MERRA-2). J. Climate, 30, 5419-5454, https://doi.org/10.1175/JCLI-D-16-0758.1.

Global Modeling and Assimilation Office, 2015a: MERRA-2 tavgM_2d_flx_Nx: 2d, monthly mean, time-averaged, single-level, assimilation, surface flux diagnostics V5.12.4. Goddard Earth Sciences Data and Information Services Center (GES DISC), accessed May 2018, https://doi.org/ 10.5067/0JRLVL8YV2Y4.

, 2015b: MERRA-2 statD_2d_slv_Nx: 2d, daily, aggregated statistics, single-level, assimilation, single-level diagnostics V5.12.4. Goddard Earth Sciences Data and Information Services Center (GES DISC), accessed March 2019, https:// doi.org/10.5067/9SC1VNTWGWV3.

—_, 2015c: MERRA-2 inst1_2d_asm_Nx: 2d,1-hourly, instantaneous, single-level, assimilation, single-level diagnostics V5.12.4. Goddard Earth Sciences Data and Information Services Center (GES DISC), accessed March 2019, https:// doi.org/10.5067/3Z173KIE2TPD.

— 2015d: MERRA-2 inst3_3d_asm_Np: 3d,3-hourly, instantaneous, pressure-level, assimilation, assimilated meteorological fields V5.12.4. Goddard Earth Sciences Data and Information Services Center (GES DISC), accessed March 2019, https:// doi.org/10.5067/QBZ6MG944HW0.

Guan, B., D. E. Waliser, J. F. Li, and A. da Silva, 2013: Evaluating the impact of orbital sampling on satellite-climate model comparisons. J. Geophys. Res. Atmos., 118, 355-369, https:// doi.org/10.1029/2012JD018590.

Hearty, T. J., and Coauthors, 2014: Estimating sampling biases and measurement uncertainties of AIRS/AMSU-A temperature and water vapor observations using MERRA reanalysis. J. Geophys. Res. Atmos., 119, 2725-2741, https://doi.org/ 10.1002/2013JD021205.

Levy, R. C., G. G. Leptoukh, R. Kahn, V. Zubko, A. Gopalan, and L. A. Remer, 2009: A critical look at deriving monthly aerosol optical depth from satellite data. IEEE Trans. Geosci. Remote Sens., 47, 2942-2956, https://doi.org/10.1109/TGRS.2009.2013842.

Lim, Y.-K., R. M. Kovach, S. Pawson, and G. Vernieres, 2017: The 2015/16 El Niño event in context of the MERRA-2 reanalysis: A comparison of the Tropical Pacific with 1982/1983 and 1997/1998. J. Climate, 30, 4819-4842, https://doi.org/10.1175/ JCLI-D-16-0800.1. 
Liu, Z., and J. Acker, 2017: Giovanni: The bridge between data and science. Eos, Trans. Amer. Geophys. Union, 98, 24-30, https:// doi.org/10.1029/2017EO079299.

Marshall, J. L., and Coauthors, 2006: Improving global analysis and forecasting with AIRS. Bull. Amer. Meteor. Soc., 87, 891-895, https://doi.org/10.1175/BAMS-87-7-891.

Mudelsee, M., 2019: Trend analysis of climate time series: A review of methods. Earth-Sci. Rev., 190, 310-322, https://doi.org/ 10.1016/j.earscirev.2018.12.005.

Parkinson, C. L., 2003: Aqua: An Earth-observing satellite mission to examine water and other climate variables. IEEE Trans. Geosci. Remote Sens., 41, 173-183, https://doi.org/10.1109/ TGRS.2002.808319.

Simmons, A. J., P. Berrisford, D. P. Dee, H. Hersbach, S. Hirahara, and J.-N. Thepaut, 2017: A reassessment of temperature variations and trends from global reanalyses and monthly surface climatological datasets. Quart. J. Roy. Meteor. Soc., 143, 101119, https://doi.org/10.1002/qj.2949.

Smith, N., W. P. Menzel, E. Weisz, A. K. Heidinger, and B. A. Baum, 2013: A uniform space-time gridding algorithm for comparison of satellite data products: Characterization and sensitivity study. J. Appl. Meteor. Climatol., 52, 255-268, https://doi.org/10.1175/JAMC-D-12-031.1.

Susskind, J., C. D. Barnet, and J. M. Blaisdell, 2003: Retrieval of atmospheric and surface parameters from AIRS/AMSU/HSB data in the presence of clouds. IEEE Trans. Geosci. Remote Sens., 41, 390-409, https://doi.org/10.1109/TGRS.2002.808236.
_ for surface and atmospheric soundings, error estimates, and quality control procedures: The atmospheric infrared sounder science team version-6 retrieval algorithm. J. Appl. Remote Sens., 8, 084994, https://doi.org/10.1117/1.JRS.8.084994.

—, G. A. Schmidt, J. N. Lee, and L. Iredell, 2019: Recent global warming as confirmed by AIRS. Environ. Res. Lett., 14, 044030, https://doi.org/10.1088/1748-9326/aafd4e.

Tian, B., 2015: Spread of model climate sensitivity linked to double-intertropical convergence zone bias. Geophys. Res. Lett., 42, 4133-4141, https://doi.org/10.1002/2015GL064119.

— E. J. Fetzer, B. H. Kahn, J. Teixeira, E. Manning, and T. Hearty, 2013a: Evaluating CMIP5 models using AIRS tropospheric air temperature and specific humidity climatology. J. Geophys. Res. Atmos., 118, 114-134, https://doi.org/ 10.1029/2012JD018607.

_ , E. Manning, E. J. Fetzer, E. Olsen, S. Wong, J. Susskind, and L. Iredell, 2013b: AIRS/AMSU/HSB version 6 level 3 product user guide. NASA JPL Tech. Rep., 40 pp., https://disc.sci. gsfc.nasa.gov/AIRS/documentation/v6_docs/v6releasedocs-1/ V6_L3_User_Guide.pdf.

- E. J. Fetzer, and E. Manning, 2019: The atmospheric infrared sounder Obs4MIPs version 2 data set. Earth Space Sci., 6 , 324-333, https://doi.org/10.1029/2018EA000508.

Zender, C. S., 2008: Analysis of self-describing gridded geoscience data with netCDF Operators (NCO). Environ. Modell. Software, 23, 1338-1342, https://doi.org/10.1016/j.envsoft.2008.03.004. 